\title{
HOW CONNECTED IS THE GLOBAL SOVEREIGN CREDIT RISK NETWORK?
}

\author{
Görkem Bostanc1 \\ Kamil Y1lmaz
}

Working Paper 1515

August 2015

This Working Paper is issued under the supervision of the ERF Directorate. Any opinions expressed here are those of the author(s) and not those of the Koç University-TÜSİAD Economic Research Forum. It is circulated for discussion and comment purposes and has not been subject to review by referees.

KOÇ UNIVERSITY-TÜSİAD ECONOMIC RESEARCH FORUM Rumelifeneri Yolu 34450 Sarıer/Istanbul 


\title{
How Connected is the Global Sovereign Credit Risk Network?*
}

\author{
Görkem Bostanc1 \\ University of Pennsylvania
}

\author{
Kamil Yilmaz \\ Koç University
}

August 19, 2015

\begin{abstract}
We apply the Diebold-Yilmaz connectedness index methodology on sovereign credit default swaps (SCDSs) to estimate the network structure of global sovereign credit risk. In particular, using the elastic net estimation method, we separately estimate networks of daily SCDS returns and volatilities for 38 countries between 2009 and 2014. Our results reveal striking differences between the network structures of returns and volatilities. In SCDS return networks, developing and developed countries stand apart in two big clusters. In the case of the SCDS volatility networks, however, we observe regional clusters among emerging market countries along with the developedcountry cluster. We also show that global factors are more important than domestic factors in the determination of SCDS returns and volatilities. Finally, emerging market countries are the key generators of connectedness of sovereign credit risk shocks while severely problematic countries as well as developed countries play relatively smaller roles.
\end{abstract}

Key Words: Sovereign Credit Default Swaps, Sovereign Credit Risk, Systemic risk, Connectedness, Network Estimation, Lasso, Elastic Net, Vector Autoregression, Variance Decomposition. JEL codes: F34, G15, C32, G22, F36

${ }^{*}$ We thank Francis X. Diebold, Christian Brownlees, Cem Cakmakli, Mert Demirer, Umut Gokcen, Han Ozsoylev, Thierry Post and Tanju Yorulmazer, participants of the Second Vienna Workshop on High Dimensional Time Series in Macroeconomics and Finance for helpful comments on earlier drafts. We also thank the Scientific and Technological Research Council of Turkey (TUBITAK) for financial support through Grant No. 111K500. The usual disclaimer applies. 


\section{Contents}

1 Introduction $\quad 1$

2 Literature Review $\quad 2$

2.1 Determinants of Sovereign credit risk . . . . . . . . . . . . . . 2

2.2 Measurement of Financial Network Structures . . . . . . . . . . . . . . . . . 4

3 Methodology $\quad 4$

3.1 Measurement of Credit/Default Risk . . . . . . . . . . . . . . . . 5

3.2 Diebold-Yilmaz Connectedness Measures . . . . . . . . . . . . . . . . . 7

3.2.1 Pairwise Directional Connectedness . . . . . . . . . . . . . 8

3.2.2 Aggregate Connectedness Measures . . . . . . . . . . . . . . 9

3.3 Estimation . . . . . . . . . . . . . . . . . . . . . . 10

3.3.1 Return and Volatility . . . . . . . . . . . . . . . . . . 10

3.3.2 Selecting and Shrinking the Approximating Model . . . . . . . . . . . 10

3.4 Graphical Display . . . . . . . . . . . . . . . . . . . . . . 11

4 Data 13

5 Static Estimation of the Sovereign credit risk Network 14

5.1 Connectedness of SCDS Returns . . . . . . . . . . . . . . . . . . . . . 14

5.2 Connectedness of SCDS Return Volatilities . . . . . . . . . . . . . 16

5.3 Comparing Connectedness of SCDS Spread Returns and Volatilities . . . . . 17

6 Dynamic Estimation of Sovereign credit risk Network 19

6.1 Dynamic Evolution of SCDS Return Connectedness . . . . . . . . . . . . . 20

6.2 Dynamics of Return vs. Volatility Connectedness . . . . . . . . . . . . 23

6.3 Network Structure of SCDS Returns on Some Critical Dates . . . . . . . . . 24

6.3.1 Bernanke's July 19, 2013 Press Conference and the Taper Tantrum . 25

6.3 .2 First Greek Bailout . . . . . . . . . . . . . . . . . . . . 27

7 Implications for the Determinants of Soverign credit risk 30

8 Conclusions $\quad 42$ 
A Appendix: Sensitivity Analyses $\quad 46$

A.1 Elastic Net Estimation . . . . . . . . . . . . . . . . . . . . 46

A.2 Tuning Parameters . . . . . . . . . . . . . . . . . 48 


\section{Introduction}

The recent sovereign debt and banking crisis in the EU periphery has intensified the need for an exhaustive measure of sovereign credit/default risk connectedness. Since there are many channels (some of which cannot be directly observed) through which a shock in one country can affect others, estimating these links is not an easy task.

A relatively new financial instrument, Sovereign Credit Default Swaps (SCDSs), has been used to measure sovereign default probabilities. SCDSs have been traded extensively in the last decade. Even though there has been a slowdown after the ban on naked SCDSs trading by the EU in November 2012, SCDSs are still viewed as important indicators of sovereign credit risk.

There is a young and growing literature on the determinants of SCDS spreads. As the literature points out, increasing spreads can be due to an increase in liquidity risk, a reduction in risk appetite as well as an increase in credit risk (Beirne and Fratzscher (2013)). However, country-specific changes in SCDS spreads generally indicate changes in the market's view of the credit risk of the country's government in question.

In this paper, we use data on SCDS spreads to estimate a market based measure of the sovereign credit risk connectedness. We add to the existing literature on several grounds. First, our study overcomes the dimensionality problem that arises from the increase in the number of countries included in the analysis. Thus, instead of picking representative countries from each region, we include all countries for whom data are available for a moderate time span. Working with a large VAR, dynamic cross-country linkages can be estimated, which has never been done in SCDS literature on this scale, to the best of our knowledge. Therefore, we go beyond aggregate fundamental data to look for the determinants of SCDS spreads and add the analysis of connectedness among the SCDSs to the literature. Moreover, since most of the previous studies focus on macroeconomic fundamentals to explain the variation in SCDSs, they cannot work with high-frequency data. Utilizing daily data, even daily jumps can be observed in the connectedness of the SCDS spreads, which are not necessarily caused by macroeconomic shocks. In addition, using the Diebold and Yilmaz (2014) framework, we are able to produce a dynamic network structure, i.e. at any point in time, we can observe the full network and analyze the changes in connectedness between any two sovereigns throughout the whole sample period. Last, we are able to display the connectedness of SCDSs in network graphs which add significantly to the understanding of the underlying network structure.

Let us summarize our major findings. First, our results show global factors are more im- 
portant than domestic factors in the determination of SCDS returns and volatilities. Second, the relative importance of global and domestic factors changes continuously, as well as the relative contribution of different sovereigns to the global factors. Third, on average, emerging market countries are the most important transmitters of sovereign credit risk shocks around the world while severely problematic countries (such as Argentina, Greece, Portugal) as well as developed countries (such as US, Japan) have relatively smaller effects. Fourth, shocks to other financial assets or indices are quickly reflected in the SCDS spreads. Therefore, adding them into the analysis do not bring considerable explanatory power as long as a large number of sovereigns are controlled for.

The remainder of this paper is structured as follows. In section 2 we review the literature on the determinants of sovereign credit risk and measures of financial connectedness. Section 3 describes the Diebold-Yilmaz connectedness index methodology and the elastic net estimation method used in this paper. In section 4 we provide a brief description of the data set we use in the empirical analysis. In section 5, we present full sample results, followed by the time-varying structure of the networks presented in section 6 . Implications of the results on existing SCDS literature are discussed in section 7. Section 8 concludes the paper.

\section{Literature Review}

Our paper adds to the literature on determinants of sovereign credit risk and estimation of network structure among financial entities. Here we briefly review the literature on each of these topics.

\subsection{Determinants of Sovereign credit risk}

The literature on determinants of sovereign credit risk is rather young. Yet, it has been growing rapidly, thanks to the emergence of SCDSs as one of the liquid derivatives in financial markets since early 2000s. The focal point of the literature is relative importance of country-specific and global factors in the determination of SCDS spreads. Hilscher and Nosbusch (2010) claim that ceteris paribus, a country with more volatile fundamentals, is

more prone to default due to weakening fundamentals. They find that volatility of terms of trade is particularly significant in determination of SCDS spreads. Aizenman et al. (2013) show the default risk of PIIGS (Portugal, Ireland, Italy, Greece and Spain) countries has increased excessively during the crisis. They attribute this 'mispricing' to expected future fundamentals of these countries. Beirne and Fratzscher (2013) claim that increased sensi- 
tivity of financial markets to fundamentals was the main culprit behind the increase in the SDCS spreads during the crisis.

In another strand of the literature, Pan and Singleton (2008) analyze the term structure of SCDS spreads (of Mexico, Turkey and Korea) and find that there are strong co-movements that cannot be explained by country fundamentals. Although they observe country specific movements in some subsamples, the remaining variation is highly correlated with indicators of global risk aversion of the investors and worldwide costs of risk. Longstaff et al. (2011) support this view by showing that a single principal component is able to explain $64 \%$ (75\% during the crisis) of the variation of SCDS spreads. They also show that the principal component of SCDS spreads has a positive (61\%) correlation with the changes in VIX index and a negative (-75\%) correlation with the US stock market returns. Augustin and Tédongap (Forthcoming), on the other hand, find that the first two principal components of a 38 country set are associated with expected consumption growth and macroeconomic uncertainty in the U.S. Ang and Longstaff (2013) find that systemic risk is smaller among the U.S. states compared to European countries although macroeconomic fundamentals are much more similar among the U.S. states. Finally, Wang and Moore (2012) claim that the U.S. interest rate is the main driving factor behind the higher correlation.

Some of the studies show the relative importance of these indicators change over time. Favero and Missale (2012) find that fundamental fiscal measures become more important as global risk aversion increases.

The studies we have discussed so far have a common important implication: SCDS spreads are determined by global factors as well as the individual country/government characteristics. Moreover, relative importance of these can change over time and across countries. But these studies fail to separately account for the domestic and global shocks in the determination of the spreads. Macroeconomic fundamentals are treated as domestic factors in these studies. However, global macroeconomic shocks can easily affect a country's fundamentals. For example, a change in American interest rates, an embargo on Russian goods or a decrease in oil prices would change the current account deficit, foreign currency stocks, tax revenues and accessibility to credit markets of another country substantially. This methodology might be useful searching for a possible mispricing; however it fails to identify what portion of the change in fundamentals is due to sovereign specific shocks and what portion is due to common shocks. Our approach overcomes this problem as we directly measure connectedness of sovereigns with each other.

In addition, these studies are not able to utilize daily or intraday data, since they explicitly 
include infrequent macroeconomic fundamentals in their samples. Moreover, their sample sizes are relatively small, therefore, they use global financial indicators and do not account for the regional financial effects completely. Third, they do not give explicit measures of the stand-alone effects of these indicators. Finally, they assume global risk indicators affect all sovereigns the same way since they cannot decompose these indicators to different sources of risk. We claim that the Diebold-Yilmaz Connectedness Index methodology overcomesthese problems.

\subsection{Measurement of Financial Network Structures}

Recently, there has been an increase in the efforts to connect the literature on the determinants of SCDS spreads with the one on the connectedness of financial assets and institutions. Alter and Beyer (2014) use Diebold-Yilmaz connectedness measures and find that connectedness between countries and banks increased with the European crisis. Moreover, they show that systemic contribution of the problematic countries decreased with the implementation of EU and IMF programs. Heinz and Sun (2014) also use Diebold-Yilmaz measures to estimate the connectedness between CESEE (Central, Eastern and Southeastern European) countries and rest of Europe. They find that spillovers between these two groups of countries were relatively small during the crisis. Cho et al. (2014) applies the same methodology on Asian SCDS markets (7 countries) and find a high level of spillovers with the exception of Japan.

Our results are on the same track with these papers. We, on the other hand, investigate a wider set of regions and analyze the interrelations among countries all around the world. The increased coverage of countries is particularly important, since shocks in a particular region can easily be attributed to global indicators when that region is not properly represented in the sample. Therefore, we would be underestimating the connectedness between regions. Second, these studies do not focus on connectedness of SCDS spread volatilities. In our paper, we study the network structure of the volatility of the SCDS spreads (as a measure of the ambiguity around credit risk of the sovereigns) as well as the SCDS spreads themselves to understand how the two differ from each other.

\section{Methodology}

In this section, we provide a discussion of our methodological approach to the measurement of sovereign credit/default risk as well as the measurement of its connectedness around the 
world.

\subsection{Measurement of Credit/Default Risk}

There are numerous channels through which a shock in one financial institution can affect another. It is quite hard to decide which ones are the most important, let alone give an exhaustive list.

That is true of the connectedness of the credit risk of sovereigns, as well. To start with, in some countries, getting reliable information about balance sheets of central and/or regional governments may not be possible, especially if the government is in fiscal distress. Second, there is an even large number of possible propagation mechanisms ${ }^{1}$. Finally, relative importance of these channels changes over time; therefore, the calculations for a unified connectedness measure need to be updated regularly. Therefore, using macroeconomic fundamentals and government balance sheet information to measure linkages between sovereigns would involve a large measurement error, omitted variable bias and risk of quickly becoming outdated.

We acknowledge that any empirical approach can only provide an approximation of the actual network structure and we aim to choose a method that does this approximation best. We think such a method should rely on market information. Instead of trying to make an insurmountable calculation with numerous observed and unobserved variables and trying to do it continuously, we can look at market outcomes, which are generated by collective computation of various individual computers reflecting buy and sell orders of informed investors. Especially in the case of SCDS trading, the traders are major bond holders with professional analysts specifically working on the fiscal positions of the governments. They have access to the most relevant information about these governments. Moreover, it is the expectations and risk behaviors of these investors that affect the degree of connectedness among sovereigns. Therefore, many of the observed and unobserved connectedness mechanisms and their relative importance to each of these investors are reflected in the market.

We not only argue that market data carries most of the information about underlying connections but also macroeconomic fundamentals and balance sheet data would not bring any more descriptive or predictive power to our study. Most of these data are published annually, semi-annually, quarterly or monthly, whereas financial markets respond to important news in minutes, if not seconds. Since the financial sectors of each country are highly

\footnotetext{
${ }^{1}$ International trade volumes, currency wars, regional security problems together with international connections of private financial entities add to the possible channels of shocks among countries.
} 
connected, the effects of a shock in one country are felt in the default expectations of another country. Therefore, as the frequency of the indicators decreases, the empirical model is less capable of correctly timing the changes in the network structure.

We prefer SCDS data over bond yields since it has been shown in the literature that SCDS spreads and bond yields converge to each other in terms of sovereign credit risk pricing over time, while SCDS market is shown to dominate the bond market in terms of price discovery (See Gyntelberg et al. (2013)). Moreover, there are cash flow differences (See Duffie (1999)) which make bonds an inconsistent indicator of sovereign credit risk ${ }^{2}$.

We use network connectedness measures that are based on variance decompositions of a large VAR of the sample which are proposed and developed in a series of papers ((Diebold and Yilmaz, 2009, 2012, 2014)). There are several reasons why we choose these measures for our analysis. First, they are intuitively appealing for being connectedness measures; they show what percentage of the future uncertainty of asset $i$ is due to shocks to asset $j$. Second, they allow the user to choose any horizon for future uncertainty; connectedness in changing horizons can be significantly different. Third, these connectedness measures are direct counterparts of the edge weights in network theory. Therefore, the output of these measures can directly be represented as a network. Fourth, as shown by Diebold and Yilmaz (2015), these measures closely relate to other popular risk measures such as CoVaR (Adrian and Brunnermeier (2008)) and marginal expected shortfall (Acharya et al. (2010)). Fifth, predictive power of these measures are among the highest (Arsov et al. (2013)) of the existing indicators, i.e. they adapt to the changes in data relatively faster. Sixth, and the most important is that Diebold-Yilmaz framework allows us to utilize high frequency market data. We have daily quotes of SCDS returns for 38 countries over our full sample period (54 sovereigns in total). Moreover, the data on SCDS spreads can be easily obtained through Bloomberg and/or Thomson Reuters terminals. Therefore, any researcher with access to one of the widely used data terminal services can easily construct his/her own sample data and start conducting research in a couple of hours.

Diebold-Yilmaz connectedness methodology can be applied to financial asset returns, volatilities as well as any other market data. Recent studies on SCDSs focus solely on spreads. We conjecture that volatilities give a complementary picture of the corresponding

${ }^{2}$ CDS spreads do not fully correspond to credit risk estimation of the market due to risk premium component inherent in the spreads. However, the ratio of the risk premium to the credit risk component is generally found to be constant in studies such as Pan and Singleton (2008) and Longstaff et al. (2011). Since we are not directly interested in the absolute magnitude of the credit risk, we can ignore the risk premium part for our analysis. 
network in SCDS spreads.

We will now provide a brief description of Diebold-Yilmaz Connectedness Measures (as presented in Diebold and Yilmaz (2014)) and introduce and briefly discuss the elastic net estimation of the VAR model to deal with the dimensionality problem (as used in Demirer et al. (2015)).

\subsection{Diebold-Yilmaz Connectedness Measures}

To estimate the connectedness of SCDS returns and volatility series, we will calculate Diebold-Yilmaz connectedness measures as used in Diebold and Yilmaz (2014). These measures use variance decompositions of vector autoregressions that will allow us to estimate any pairwise connectedness present in our sample.

Using VARs has important advantages. First, we acknowledge the simultaneity in the determination of spreads which is crucial in any financial market. Second, we control for all the variables in the sample so that what we find is the pure connectedness between the two sovereigns. That is, two sovereigns that are highly connected with another sovereign are not necessarily found to be connected with each other in our method. Therefore, we do not find spuriously high connectedness measures which result from a common shock transmitter; we cannot achieve this by simply looking at pairwise correlations. We also control for the lags of dependent variable, therefore, we find a nonzero coefficient if the variable of interest is able to explain more than what is explained by the AR structure of the dependent variable itself.

We could have also used a VARX model, where we include high frequency global indicators such as stock market and industrial indices of various groups of sovereigns as control variables. The literature finds strong evidence on the effects of real and financial sectors all around the world to the sovereign credit risk. However using a simpler VAR approach has important advantages over more complicated ones.

First, the effect of shocks in financial and real sectors of a country is already reflected in its SCDS. Moreover, we expect such shocks to be reflected on that particular country's SCDS before others. Therefore, we already account for the economic shocks that are originated from our sample countries. Second, we are mostly interested in the propagation mechanism instead of the origin of the shock (since the origin is generally easier to spot). We accept that there can be shocks that cannot be attributed to any particular sovereign (such as an increase in the global risk aversion of investors). However, some countries react to these changes faster and their reaction shapes how the remaining countries will react. Therefore, 
we can see which sovereigns lead the markets so that the investors watch their movements to decide their actions on assets of other sovereigns. Finally, we have included returns for important stock market indices (such as S\&P 500, Dow Jones Industrial Average and EURO Stoxx 50) as well as the VIX volatility index returns in our VAR and have seen that these measures are very loosely connected with the SCDS returns in our sample. That is, if we ensure a considerable representation in our analysis, these indices do not bring extra information to the picture. We will discuss this issue further in Section 7.

We follow Diebold-Yilmaz approach with three lags ${ }^{3}$ and use generalized variance decompositions to obtain connectedness measures from the VAR model. Proposed by Pesaran and Shin (1998), generalized VAR approach produces variance decompositions which are invariant to ordering of variables in the VAR model. It allows for correlated shocks but also separates the effects of each shock for the purposes of analysis. Since the shocks are not orthogonal, the row sum of the entries of the variance decomposition matrix do not add up to $100 \%$, but we normalize them by dividing all entries of the variance decomposition matrix with the corresponding value of the row-sum.

\subsubsection{Pairwise Directional Connectedness}

Variable $j$ 's contribution to variable $i$ 's $H$-step-ahead generalized forecast error variance, $\theta_{i j}^{g}(H)$, is calculated as

$$
\theta_{i j}^{g}(H)=\frac{\sigma_{j j}^{-1} \sum_{h=0}^{H-1}\left(e_{i}^{\prime} A_{h} \Sigma e_{j}\right)^{2}}{\sum_{h=0}^{H-1}\left(e_{i}^{\prime} A_{h} \Sigma A_{h}^{\prime} e_{i}\right)}, \quad H=1,2, \ldots,
$$

where $\Sigma$ is the covariance matrix for the error vector $\varepsilon, \sigma_{j j}$ is the standard deviation of the error term for the $j^{\text {th }}$ equation, $A_{h}$ is $h$ th step moving average coefficient matrix and $e_{i}$ is the selection vector with one as the $i^{\text {th }}$ element and zeros otherwise.

We can normalize this measure to get well-defined percentages:

$$
\tilde{\theta}_{i j}^{g}(H)=\frac{\theta_{i j}^{g}(H)}{\sum_{j=1}^{N} \theta_{i j}^{g}(H)} .
$$

where $\sum_{j=1}^{N} \tilde{\theta}_{i j}^{g}(H)=1$ and $\sum_{i, j=1}^{N} \tilde{\theta}_{i j}^{g}(H)=N$ follow by construction. We call $\theta_{i j}^{g}(H)$ the 'pairwise connectedness' from variable j to variable $\mathrm{i}$.

Please note that we measure directional connectedness. Therefore, we do not assume

\footnotetext{
${ }^{3}$ We present the sensitivity of our results to the choice of number of lags in the Appendix.
} 
the effect of variable $i$ on the variable $\mathrm{j}$ is identical to the effect of variable $\mathrm{j}$ on variable $\mathrm{i}$. Our estimations show that let alone being equal, there is no clear pattern between these two effects. Therefore, any method which tries to estimate an un-directed network will produce biased estimates while conveying substantially less information.

\subsubsection{Aggregate Connectedness Measures}

After calculating the pairwise connectedness measure between variables $\mathrm{i}$ and $\mathrm{j}$, the possibilities are endless. First, one can look at systemic measures, such as, what is the total directional connectedness from variable i to all remaining variables or what is the total directional connectedness to variable $\mathrm{i}$ from all remaining variables. We will call them as 'to connectedness' of variable $i$ and 'from connectedness' of variable $i$, respectively. ${ }^{4}$ Simple examples in our framework would be the percentage effect from Spain to the whole sample and the percentage effect from the whole sample to Spain. These give us 'to connectedness' and 'from connectedness' measures of Spain. The 'to connectedness' quantifies what percentage does Spain holds in the determination of SCDS spreads (or volatilities) of the whole sample. The 'from connectedness' quantifies what percentage of the SCDS spread (or volatility) of Spain is determined by shocks in other countries in the sample. Therefore, one can directly use these measures to answer questions about the determinants of sovereign credit risk. Relatively less systemic measures (such as the percentage effect from South America to Spain) can be calculated accordingly by summing over related samples.

We might be interested in an even more systemic measure, such as what is the overall importance of shocks originating in other countries on determination of SCDS spreads (or volatilities). We calculate the total connectedness index as

$$
C(H)=\frac{\sum_{\substack{i, j=1 \\ i \neq j}}^{N} \tilde{\theta}_{i j}^{g}(H)}{\sum_{i, j=1}^{N} \tilde{\theta}_{i j}^{g}(H)}=\frac{\sum_{\substack{i, j=1 \\ i \neq j}}^{N} \tilde{\theta}_{i j}^{g}(H)}{N} .
$$

We call this total connectedness as system-wide connectedness, which is simply the average of total directional connectedness measures whether "to" or "from". 5

\footnotetext{
${ }^{4}$ Note that 'from connectedness' measure cannot be greater than $100 \%$ by construction while there is no informative constraint on the 'to connectedness' measure.

5 These measures complement each other since a variable's 'to connectedness' is necessarily another variable's 'from connectedness'. Therefore, the averages of these measures over the sample are necessarily equal. The readers should refer to Diebold and Yilmaz (2014) for a detailed description of the measures and their properties.
} 


\subsection{Estimation}

Our analysis of connectedness focuses mostly on the daily difference of log SCDS spreads (which we will call daily SCDS returns), but we also obtain results with SCDS return volatilies to compare them with the results we obtained from the returns.

\subsubsection{Return and Volatility}

In our implementation of the DYCI model, we use the 'daily difference of log SCDS spreads' rather than the daily SCDS spreads themselves as the key variable of interest. The daily SCDS spreads variable itself has unit root (Gyntelberg et al. (2013)), but the hypothesis of unit root is strongly rejected for the difference of log SCDS spreads. However, in order to avoid a rather long name for the key variable of interest, we call it 'SCDS spread returns' or 'SCDS returns,' in short, instead of 'the daily difference of log SCDS spreads.'

The second variable of interest for us is the volatility of SCDS returns. However, as the daily volatility is not an observed variable we need to estimate it. We use range volatility estimate since we are able to utilize intraday data. We estimate daily range volatilities following the method developed by Garman and Klass (1980) which utilizes daily (open, high, low, close) spread data. ${ }^{6}$ Financial asset volatilities have a right-skewed distribution, therefore, we take natural logarithms before using them in a VAR model.

\subsubsection{Selecting and Shrinking the Approximating Model}

We can use generalized indices for the omitted parts of the world, as the literature currently does. However, we would be aggregating that part of the world into one series and cannot identify the particular reasons behind significant financial events. Similar to Tolstoy's world, safe havens are all alike; whereas every problematic country is problematic in its own way. Hence correctly accounting for the origin of the shocks can also help us identify the main channel(s) in the propagation of shocks. However, increasing the number of variables, in a VAR setting, quickly consumes degrees of freedom and we need a longer period to increase the number of observations. Lengthening the sample window, on the other hand, precludes the correct estimation of the change in the coefficients over time. To overcome this problem, we follow Demirer et al. (2015) and estimate sparse VAR of SCDS returns/volatilities using the elastic net estimator.

\footnotetext{
${ }^{6}$ One can use high frequency (sampled every 5 or 10 minutes) spread data to calculate realized volatilities. However, data at this frequency is available for a limited amount of sovereigns and for a limited amount of time.
} 
The elastic net estimator (Zou and Hastie (2005)) is a hybrid of shrinkage and selection methods. It chooses $\beta$ vector that solves

$$
\hat{\beta}_{\text {Enet }}=\arg \min _{\beta}\left(\sum_{t=1}^{T}\left(y_{t}-\sum_{i} \beta_{i} x_{i t}\right)^{2}+\lambda \sum_{i=1}^{K}\left(\alpha\left|\beta_{i}\right|+(1-\alpha) \beta_{i}^{2}\right)\right) .
$$

Elastic net estimation combines the lasso $L_{1}$ regularization with the ridge $L_{2}$ regularization. It has two tuning parameters, $\lambda$ and $\alpha \in[0,1]$. The estimator is equivalent to lasso when $\alpha=1$ and to ridge when $\alpha=0$. While lasso may select only one of the strongly correlated predictors and drop the others, elastic net makes sure that they are in or out of the model together. In our analysis we will take $\alpha=0.5$ without cross validation and use 10 -fold cross validation to choose the value of $\lambda^{7}$.

Adaptive elastic net does not directly minimize the sum of squares, thus estimated coefficients are generally biased. There are reasons for overlooking the potential bias in our analysis.

First, elastic net applies shrinkage mainly on small coefficients forcing them to zero, therefore, underestimates smaller ties between sovereigns. However, even though elastic net allows us to estimate a sparse VAR, the resulting network is not sparse because entries in the variance decomposition matrix is determined not only by the estimated coefficients of the VAR, but also by the variance covariance matrix estimate. Second, the higher coefficients are expected to be scaled down according to their sizes, therefore, relative importance of domestic and global factors does not necessarily change. In addition, we still expect to see the sovereign with higher coefficient as the one with the thicker edge on our network graph. Third, the reader may inquire whether adaptive elastic net can be used on VAR estimation as it is used on simple linear regressions. Furman (2014) provides evidence that elastic net does not preclude efficient equation by equation estimation of VAR and the impulse response functions produced are valid. We provide basic sensitivity analyses regarding the elastic net estimator in Appendix A.

\subsection{Graphical Display}

In our empirical analysis, we will present graphs with as many as 151 nodes and as many as $151^{2}$ edges. Presenting the whole network with all the edges would not be very informative

\footnotetext{
7 We can also cross validate $\alpha$, however it increases the computation time substantially while adding little to the estimation quality. Moreover, as long as positive coefficients exist for both the ridge and lasso penalties, the estimator works consistently.
} 
and would require a high level of attention to identify patterns in the network structure. Therefore, we will present a fraction of the existing edges by removing the weakest ones in the graphs. Whenever we compare two graphs, we make sure they have the same percentage of edges visible. In addition, all network statistics will be calculated for the full network.

We use Gephi, an open-source software for visualizing and analyzing large network graphs. We study complete, weighted, directed networks and use node size, node color, edge thickness, edge arrow size and edge color to convey extra and hard-to-spot information about the graph together with the node location.

\section{Node Size Indicates Credit Rating}

We use end-of-sample period Fitch credit ratings of sovereigns to determine node sizes. According to these ratings, a sovereign with higher credit rating (closer to AAA) has a smaller node size while a sovereign with lower credit rating (closer to D) has a bigger node size. We intend to emphasize problematic countries in a given period with this approach ${ }^{8}$.

\section{Node Color Indicates Total Directional Connectedness "To Others"}

The node color indicates total directional connectedness "to others" ${ }^{9}$ A sovereign that is less influential overall will be colored close to bright green while a highly influential sovereign will be colored close to dark red as in Figure 1.

Figure 1: Color Spectrum

\section{Node Location Indicates Strength of Average Pairwise Directional Connectedness}

Locations of the nodes are determined by the ForceAtlas2 algorithm of Jacomy et al. (2014) as implemented in Gephi. The algorithm finds a steady state in which repelling and attracting forces exactly balance each other, where $(i)$ nodes repel each other, but $(i i)$ edges attract the nodes they connect based on the average pairwise directional connectedness between the

\footnotetext{
${ }^{8}$ Undoubtedly, there is no correct way of transforming letter ratings into numbers, therefore, the actual sizes of the nodes are not directly interpretable. However, we can make sure a country with a lower credit rating will always have a bigger node size than a country with a higher credit rating. We transform credit ratings into numbers using the table at www.tradingeconomics.com.

${ }^{9}$ Colors range from 3DRA02 (bright green), to E6DF22 (luminous vivid yellow), to CF9C5B (whiskey sour), to FC1C0D (bright red), to B81113 (dark red; close to scarlet). We determine the thresholds by taking the $25 \%, 50 \%$ and $75 \%$ percentiles of the 'to' connectedness measures of all the countries throughout the dynamic analysis. Therefore, node colors are comparable across graphs.
} 
two nodes. At the steady state equilibrium, we expect nodes with higher pairwise directional connectedness values to be closer to each other ${ }^{10}$.

\section{Edge Thickness Indicates Average Pairwise Directional Connectedness}

Edge color is lighter for the weakest links and same for all the others. Since we represent average pairwise directional connectedness with edge thickness, edge color is used just for the sake of clearer visuals.

Edge Arrow Sizes Indicate Pairwise "To" and "From" Directional Connectedness

\section{Data}

SCDS intraday data are not readily available for all sovereigns and throughout the period they have been traded. For that reason we use daily data obtained through the Bloomberg terminal. We interpolate the missing days of a series whenever the missing segment of the series is not more than 8 consecutive days. However, if the missing data segment is longer than 8 days consecutively, we drop the sovereign from our sample. Unavailability of data for consecutive weeks is common for some sovereigns, especially in the case of SCDS return volatilities. Therefore, we need to reach a compromise between the number of sovereigns in our sample and the length of the sample period. We use different sample periods for different analyses in our study.

The main dynamic (rolling window) and full sample analyses are undertaken using data for 38 countries from February 2009 to April 2014. We estimate dynamic connectedness measures with a fixed sample of sovereigns, so that these measures are not affected by changes in the sample size as we roll the sample windows.

We also conduct both dynamic and full sample analyses of connectedness using data for 17 countries for a long sample period that spans from June 2005 to September 2014. Despite fewer number of sovereigns included in the sample, we nevertheless start the dynamic connectedness analysis in the pre-crisis period. As such, we are able to observe the dynamic behavior of the connectedness measures during the critical junctures in the development of the U.S. subprime crisis.

In daily network estimations, we use all countries that have available data in that window (150 day) with a maximum of 54 countries. For instance, we use 50 sovereign SCDSs in

\footnotetext{
${ }^{10}$ The steady state node locations depend on initial node locations and are not unique. However, this shortcoming is irrelevant, as we are interested in relative -not absolute- node locations in equilibrium. The relative positions of nodes are similar across equilibria.
} 
the network estimation of 26 May 2010, since that 50 particular sovereigns have full data availability for the previous 150 days and the other four sovereigns do not.

Moreover, whenever we estimate the network of returns, we try to fill the missing data from the Markit database. Our Markit subsample does not have intraday data that allows us to calculate volatilities. Nonetheless, whenever we are comparing return connectedness with volatility connectedness, we make sure to use identical samples of sovereigns and periods.

As stated above, throughout the paper we will focus on the analyses conducted using data for 38 countries. We will explicitly emphasize if we use a larger or smaller sample for the network estimations.

\section{Static Estimation of the Sovereign credit risk Net- work}

In this section, we use the whole sample period to estimate an 'average' network of the entities. We realize that pairwise connectedness between any two sovereigns can significantly change over time but we can still observe the basic patterns in the related period using the whole sample. Moreover, due to large number of observations, we are safer in terms of degrees of freedom. Hence, we can check the reliability of rolling window analysis by investigating whether unanticipated differences exist between any of the windows and the full sample.

We present the full-sample SCDS return and return volatility connectedness graphs in Figures 2(a) and 2(b), respectively. We first discuss the two graphs separately, before going ahead and compare them. Throughout this section, we will only show the thickest $25 \%$ of the edges in order to make sure that we obtain a discernable view of the network graphs ${ }^{11}$.

\subsection{Connectedness of SCDS Returns}

The overall picture in the return graph is striking. The sovereigns are divided into two big clusters; the one on the left consists of developed EU countries and one on the right consists of developing countries. The connectedness across the two clusters is quite weak, as shown by thin pairwise edges between the members of the two clusters. Japan stands further away from other developed countries, with some weak connections with developing countries.

The big developed country cluster has small clusters in itself. Portugal, Ireland, Italy,

\footnotetext{
${ }^{11}$ Even though $75 \%$ of the edges are not shown, the thickest edges dropped from the graphs account $3.11 \%$ and $2.52 \%$ (of the forecast error decomposition) for return and volatility graphs, respectively.
} 
and Spain (from now on we will call them as PIIS countries) ${ }^{12}$ form a cluster in the upper region of this cluster. Consistent with their lower sovereign credit ratings PIIS countries have larger nodes compared to other developed countries. They are tightly connected with each other as expected. We can also see that the safer countries that are affected by the EU crisis the most (Belgium, France, Netherlands) are the closest ones to PIIS countries. As revealed by their red colored nodes, Italy and Spain transmit shocks more than they receive in the PIIS sub-cluster.

Although the credit rating of Belgium is considerably better than the PIIS countries, as a result of the political crisis that lasted from 2007 to 2011 and had raised serious questions about the viability of the country in one piece, it is one of the biggest shock transmitters in the region with Italy and Spain.

Ireland and Portugal have lower total directional return connectedness to others. This may seem inconsistent with the troubles their respective countries suffered after the global financial crisis of 2009. However, this result is consistent with what we will discuss in detail in the rolling-window analysis of connectedness below: Once a country experiences a sovereign debt crisis, it loses its ability to generate SCDS return connectedness to others.

Various papers claim shocks in the US are the main driving force behind SCDS spreads of many countries. These claims do not imply that changes in US credit risk is causing changes in other countries' credit risk. Rather they imply that changes in market conditions in the US lead to changes in other countries' credit risk by changing the cost and availability of funds for these countries. We could not include US in our full sample due to data unavailability, however in particular windows where it is included, US is one of the disconnected countries in SCDS networks just like Japan.

Developing country cluster of the full sample return connectedness graph also has some interesting characteristics to highlight. As can be deduced from their crimson red node colors, three relatively big emerging market economies, namely, Russia, South Africa and Turkey, generate the highest directional return connectedness to others. These countries have high pairwise connectedness with each other, but they also have high SCDS return connectedness to other countries both in (Hungary, Poland, Romania, Bulgaria, Kazakhstan, and Croatia) and out (Latin American countries) of their geograhical neighborhood.

The most tightly connected countries in the whole graph are five Latin American countries, namely, Brazil, Mexico, Panama, Peru and Colombia. The edges between these coun-

\footnotetext{
${ }^{12}$ Greece is not present due to lack of available data for the whole sample. Later, we will discuss Greek SCDS returns in our rolling sample analyses.
} 
tries are the thickest in the whole return connectedness graph. Argentina, Venezuela and Chile are located away from this group of five countries. They do not have high directional connectedness to other Latin American countries, but they receive high directional connectedness from those countries. The cases of Argentina and Venezuela support our hypothesis: they are so problematic that the markets do not follow their situation anymore. Chile is also relatively more developed compared to the region. Being a stable country, Chile does not affect the other countries' credit risk considerably.

CESEE countries are mostly located around the periphery of the developing country cluster and they are not tightly connected with the developed side of the EU. This result supports the observation made by Heinz and Sun (2014), which stated that spillovers between EU periphery and CESEE countries were low during the sovereign debt crisis.

Interestingly, being a developed country, the node representing Japan's SCDS returns is closer to the developing country cluster than the developed country cluster. However, it is still strikingly disconnected from this group as well. Although it has the biggest debt to GDP ratio in the globe, the changes in Japan's SCDS spreads are not affecting other countries. Nearly all of the East Asian countries are dropped from the full sample analysis due to lack of intraday data to calculate volatilities. However, we show in the rolling sample analysis that even when they are included, Japan remains disconnected from the whole graph. This result is also supported by the findings of Cho et al. (2014) focusing on the connectedness of seven Asian SCDS markets.

\subsection{Connectedness of SCDS Return Volatilities}

Volatility network in Figure 2(b) shows that there are at least three main clusters. Developed European country cluster is located in the lower part of the graph. The structure of this cluster is nearly identical to the return graph in itself. PIIS countries lose their importance in shock transmittance in terms of volatility. Portugal loses its importance completely. A more uniform transmitter-receiver relation emerges overall in the developed country cluster.

Latin American countries are located on the left. Chile, Venezuela and Argentina are still receivers of the shocks rather than transmitters. Brazil stands out as an important transmitter of volatility shocks, while Colombia, Peru, Panama and Mexico lose some importance compared to the return connectedness graph.

In the upper portion, we have Russia, South Africa and Turkey together with CESEE countries. Note that the three big emerging market economies continue to be the closest ones to Latin American countries in the volatility connectedness graph as they were in the return 
connectedness graph. Turkey is the most important generator of volatility connectedness to others, followed by Russia, South Africa, Brazil (and Belgium in the developed country cluster). In the right hand side, Lithuania, Latvia, Slovakia and Slovenia stand out from the main cluster of the CESEE countries. These countries could also be regarded as a fourth cluster in the volatility graph. Finally, similar to the case with SCDS returns, Japan has very little connectedness in SCDS volatility.

\subsection{Comparing Connectedness of SCDS Spread Returns and Volatil- ities}

Comparing network structures of SCDS spread returns and volatilities, one can see clear distinctions. First, in the return connectedness graph, countries are divided into two clusters, namely, developed and developing countries. The level of connectedness across these two big clusters is low. However, the countries inside each cluster are well connected with each other. On the other hand, there are clearly at least three ${ }^{13}$ main clusters in the volatility connectedness graph, with weaker links among them.

Statistical measures of network community structure also support what one can observe with naked eye. As a network graphing software Gephi detects the presence of two and three communities in the return and volatility connectedness graphs. Modularity (excess fraction of the edges in detected communities relative to a graph where the existing links are distributed randomly) of the return graph is $0.17,{ }^{14}$ while modularity of the volatility graph is 0.28 , i.e. detected communities have an extra $11 \%$ of links in the volatility graph compared to the return graph.

The most subtle implication of this structure is that shocks to developing countries' SCDS returns tend to generate connectedness to developing countries around the world, whereas shocks to their SCDS volatilities generate connectedness to their geographical neighbors mostly. This is a result of the fact that while SCDS returns measure the change in the credit risk of the sovereigns, SCDS return volatilities show the uncertainty about their credit risk. When there is a shock to a sovereign's credit risk it is likely to affect countries that fall in the same risk group irrespective of its geographical location. When a sovereign's credit risk becomes more uncertain, its impact is likely to be felt more in its geographical neighborhood with much less implications for other countries in its risk group.

\footnotetext{
${ }^{13}$ In the next section, we see that Asian countries form a fourth distinct cluster in the windows they are included.

14 Algorithm by Blodel et al. (2008) have been used for community detection and modularity calculation.
} 


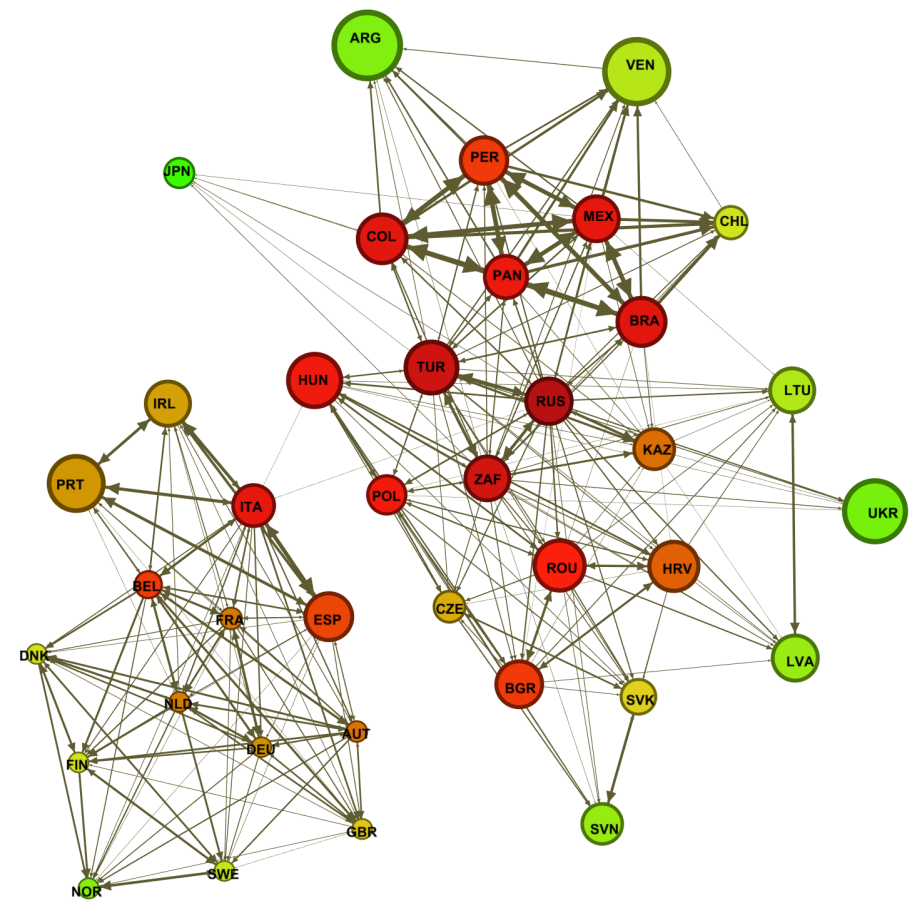

(a) Return Connectedness (scale $=600)$

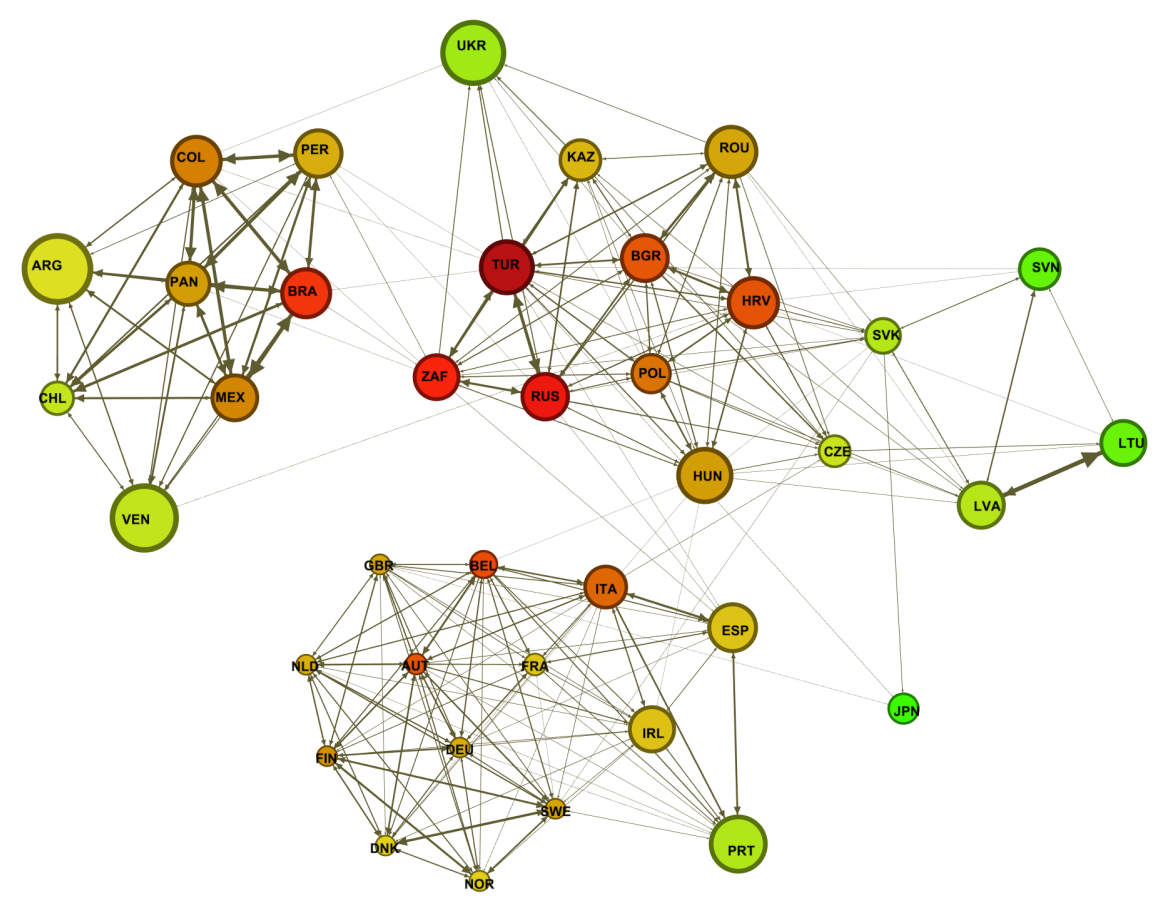

(b) Volatility Connectedness (scale $=400)$

Figure 2: Sovereign CDS Network, 2009-2014 (25\% of the edges visible) 
Let's take Russia as an example. In the full sample, Russian SCDS returns generate connectedness to Latin American countries as well as countries in its geographical neighborhood. A look at the volatility connectedness graph, on the other hand, makes it clear that Russian SCDS return volatility generates connectedness mostly in its geographical neighborhood, with very little connectedness towards the Latin American countries.

Second, edges overall are thicker in the return graph compared to the volatility graph. The total connectedness index is indeed higher in the returns compared to the volatilities. While on average $86.4 \%$ of forecast errors are attributed to other countries in the return graph, the number is $77.6 \%$ for the volatility graph. This result implies the SCDS returns are more tightly connected with each other than the SCDS return volatilities. ${ }^{15}$ Such an outcome is consistent with SCDS return being a better measure of sovereign credit risk than the SCDS return volatility.

As a side exercise, we normalize the edges, so that overall connectedness in both graphs are the same and check which sovereigns are relatively more connected in returns and in volatility. Czech Republic, Lithuania, Slovakia and Slovenia have lower 'from connectedness' in volatility than returns, which shows that their SCDS volatilities are relatively less affected from volatility shocks to other countries in comparison with the effects of other countries' return shocks on their returns. We also see that, while the 'to connectedness' in volatility of the majority of the countries is lower than their 'to connectedness' in returns, a small minority (Baltic countries and Argentina, in particular) have higher volatility connectedness to others than return connectedness. However, as their 'to connectedness' measures are much lower than the corresponding measures of other countries, their net connectedness with other countries continue to be negative, meaning that they continue to be on the receiving end of both return and volatility shocks.

\section{Dynamic Estimation of Sovereign credit risk Net- work}

The full-sample static analysis only gives us a measure of average connectedness of sovereign SCDS returns and/or volatilities. However, the relative and absolute importance of sovereigns in transmitting shocks may change over time. For the same reason, the relative importance of domestic and global factors in determining sovereign credit risk may also change over time.

\footnotetext{
15 Cho et al. (2014) also find a similar result for Asian countries using a lower frequency volatility estimator based on daily data instead of intraday data.
} 
Thus, one cannot assume that SCDS spreads are generated by the same distribution and hence the estimated VAR coefficients stay the same for years. In order to track how return and volatility connectedness measures change over time we need to undertake a dynamic analysis of connectedness.

We adopt the simple rolling sample window approach to capture the dynamics of connectedness measures over time. In order to achieve a balance between trend spotting and having reasonable degrees of freedom, we choose the window length to be 150 days. 150 observations roughly correspond to 7 months. We realize 7 months is still a long period to assume a constant VAR model. However, since we use daily data, we are still able to catch changes in connectedness measures over time ${ }^{16}$.

\subsection{Dynamic Evolution of SCDS Return Connectedness}

The system-wide connectedness index (which is defined as the percentage of the forecast error variance attributed to shocks originating from other sovereigns, on average) is an intuitively appealing measure of the role played by shocks to other country SCDSs in the determination of SCDS returns as opposed to the tole played by domestic factors. Two system-wide connectedness measures for SCDS returns are presented in Figure 3.

The shorter red line is our main focus in this section. It is the system-wide connectedness index for a sample of 38 sovereigns from February 2009 to April 2014. The first important result of the graph is that the system-wide connectedness index is never below $65 \%$, which implies that global factors account for the bulk of the movement in SCDS returns. Moreover, during the global financial crisis and the European debt and banking crises, until 2013 the index was always above $79 \%$. This result strongly supports the literature which argues that the global factors are very critical in the determination of sovereign credit risk.

Second, during relatively problematic periods, the importance of global factors becomes even more apparent. Tense periods of the EU crisis can easily be spotted in the graph as having a significant increases in the return connectedness during these periods. In particular, we can distinguish two sudden increases in our graph, which correspond to important turning points in the last decade. The earlier turning point is in the beginning of May 2010, where system-wide connectedness index has increased 5 percentage points in six working days after a relatively flatter increase during April 2010. A slow but steady increase in the index starts

\footnotetext{
${ }^{16}$ We also replicated our results with smaller and larger windows and using simple exponential smoothing with different VAR coefficients, but only the smoothness of the graph changed; the index experiences significant increases during in the same periods.
} 
with first bailout package talks with Greece, two weeks earlier than the official request for a bailout. The official bailout request did not affect the connectedness as much (probably because it was expected). However, after the agreement of a bailout on May 2, which included tough austerity measures and followed by country-wide protests and a 48 hours long strike, the system-wide connectedness quickly climbed up.

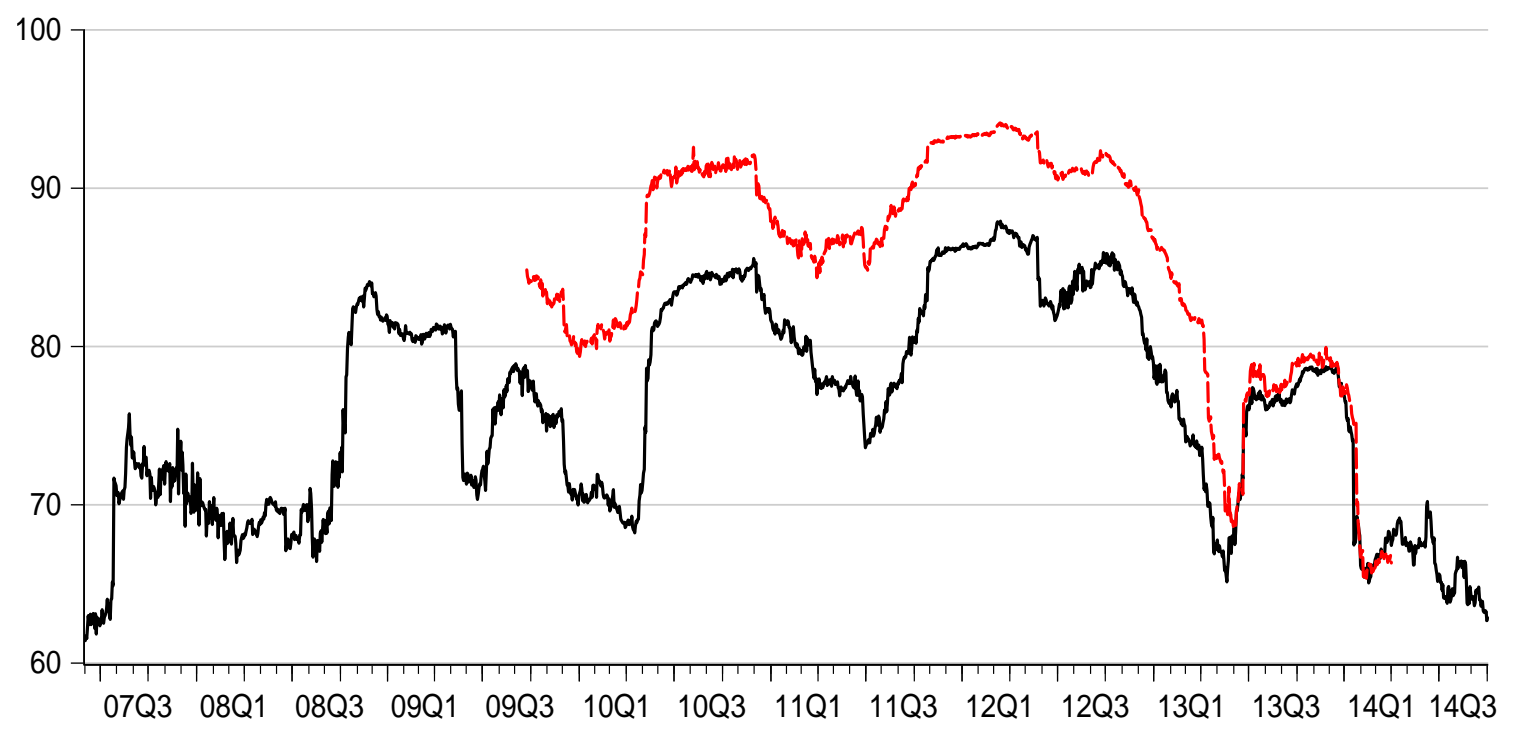

Figure 3: System-wide Connectedness of SCDS Returns, Comparing Samples

The second turning point was in June 2013, where system-wide connectedness increased by 6 percentage points in one day. This point corresponds to the day after Bernanke hinted the tapering of quantitative easing policy by the Fed. Although the index does not reach the heights of the EU crisis, the increase is still the biggest daily jump in the given sample.

The longer black line in Figure 3 corresponds to an analysis with 17 countries $^{17}$ covering the period from June 2007 to September 2014. In calculating and displaying this index for a smaller subset of countries we would like to show the general tendency of the system-wide connectedness measure over a longer period and draw conclusions about the differences with the 38-country analysis in the period they coexist. In addition to the two critical points that we have discovered with the 38-country analysis, we detect two other critical points where system-wide connectedness heightens quickly. The first additional point corresponds to the liquidity crisis of 2007. July and August 2007 was the period when the doubts about sub-prime lending built up. On July 26, 2007, the overall percentage of global shocks in the

\footnotetext{
17 These are the sovereigns which have intraday data availability from 2007 to 2014 .
} 
decomposition of sovereign credit risk increases nearly 7 points. In July 26, Bear Stearns seized its assets from two of its problematic funds. This liquidation has caused a $4.2 \%$ fall in Bear Stearns shares in one day. In the following day, global stock markets have seen a big decline. Then, within two weeks on August 9 BNP Paribas decided to freeze three of its investment funds that were heavily exposed to the US subprime mortgage market. The index increased again to reach $75 \%$ by August 24 .

The second additional critical period was between 3rd and 10th of October 2008 where the connectedness index increased by 6 percentage points in one week. After Lehman's collapse, on October 3, President Bush has signed the Emergency Economic Stabilization Act of 2008 which includes a $\$ 700$ billion bailout program. European governments tried to initiate last-minute measures to cover their financial sectors from a possible contagion, but the tension also increased in those countries.

Two series roughly follow the same pattern in the periods they coexist. This observation encourages us to presume that co-movement would also continue if we were able to estimate the connectedness index for 38 countries in other periods. We can also presume that at least the sign of change in the relative importance of domestic and global factors can be estimated with a smaller sample of sovereigns.

On the other hand, magnitude of the overall connectedness measured with 38 countries is quite different than the one measured with 17 countries. There is roughly a 7-10 point difference between the two series throughout the EU Crisis. However, from mid-March 2013 to early June 2013 the gap between the two series gradually closed from around 8 percentage points to less than two percentage points. The graph clearly shows that omitted sovereigns in the sample significantly affect the bias in our estimation. The bias can be positive or negative but we must remember that the system-wide connectedness index is an average measure $^{18}$. The 'to' and 'from connectedness' measures of individual sovereigns (estimation of which is our main objective in this paper) are always underestimated whenever a sovereign is left out. Thus, we find lower bounds for the percentage of global factors in determinants of credit risk of each sovereign. By including a large number of sovereigns, we try to find

\footnotetext{
18 Suppose a single sovereign is omitted from the analysis. If that sovereign is strongly connected to the rest of the sample so that its from connectedness is greater than the average of the rest of the sample, then we underestimate the system-wide connectedness by omitting it. On the other hand, if the country's from connectedness is lower than the sample average, we need to analyze relative effects of two mechanisms. First, there is a positive effect on system-wide connectedness index due to exclusion of a sovereign with a lower from connectedness. Second, since there is one less explanatory variable for every sovereign, the average from connectedness of the sample is expected to decrease. Therefore, the overall connectedness index may increase or decrease. The same argument applies for multiple omitted sovereigns with small adjustments.
} 


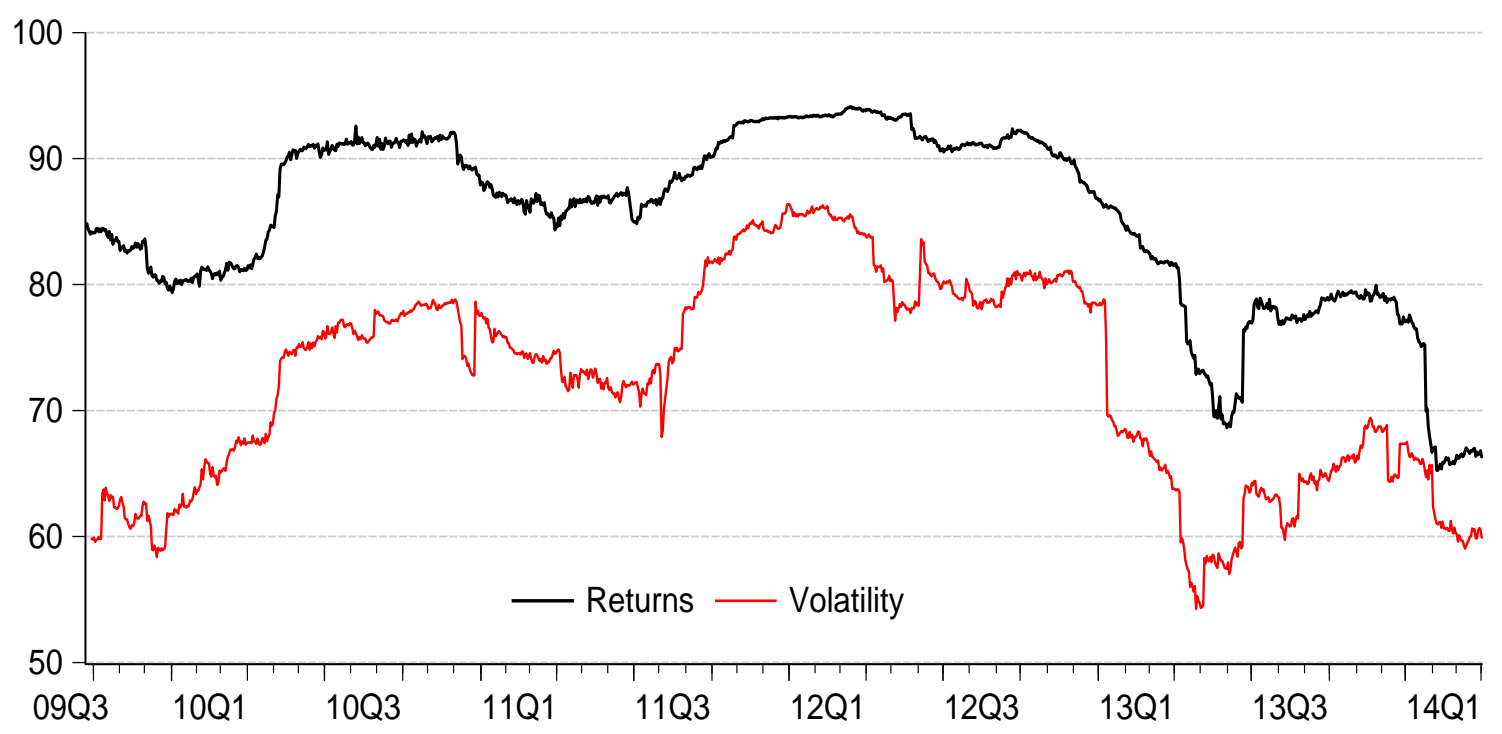

Figure 4: System-wide Connectedness of SCDS Returns and Return Volatilities

the highest lower bound that is feasible to estimate.

Omitting a small and unimportant country would not create significant problems in terms of estimation, however omitting central countries can distort our analysis significantly. Indeed, omitting many EU member countries including PIIS countries in the 17-country analysis creates a significant difference during the global financial crisis and the EU debt and banking crisis, but the amount of bias decreases significantly once the European debt and bank crisis starts to subside down by late 2012, following the ECB's direct and indirect interventions in the European sovereign debt markets. Furthermore, most of the countries that were affected from the news about a potential US monetary policy tightening in June 2013 were mostly emerging market economies that were already included in the 17-country sample. As a result, the system-wide connectedness indices for both the 17- and 38-country samples reflected the increase both the tapering

\subsection{Dynamics of Return vs. Volatility Connectedness}

We present return and volatility connectedness indices of 38 countries in Figure 4, where the solid and dashed lines represent indices computed using returns and volatilities respectively. The comparison of the return and volatility connectedness plots help us identify two important results.

First, SCDS returns are affected more from global factors compared to volatilities. We 
have seen in the preceding section that the modularity of the volatility network was significantly higher than the modularity of the return network. Acemoglu et al. (2015) show that one is more likely to observe within-cluster contagion in networks where there are multiple clusters (local communities) in which the members are strongly connected with each other and relatively less connected with the members of other clusters. In this vein, volatility shocks are mostly transmitted within the same cluster, and much less across different clusters. As the return connectedness graph has lower modularity, the return shocks are transmitted within the same cluster as well as across the other clusters. To sum up, network structure might be one of the reasons why domestic factors are more important in the determination of SCDS volatilities compared to SCDS returns.

Second, the gap between the two connectedness plots stays more or less unchanged over time. This indicates, in a long term perspective, shocks that affect SCDS returns also affect the SCDS volatilities so that the two series follow similar dynamic behavior. However, return connectedness plot is considerably smoother than the volatility connectedness plot. We observe some sudden decreases followed by sudden increases in the volatility plot. The network structure might be effective here. It might take a while before the shocks are transmitted from one portion of the network to the other. Therefore, when a shock occurs, a sudden movement of volatility is realized in one cluster of the graph which is uncorrelated with the rest of the sovereigns. However, as time progresses and the shocks are transmitted further, SCDS volatilities start to move in the same direction which causes an increase in the connectedness measure. The same mechanism also works in the case of spread returns, however, it takes a smaller amount of time for the shocks to be transmitted, which brings increases or decreases together. Thus, smoothness is preserved.

\subsection{Network Structure of SCDS Returns on Some Critical Dates}

In this section we present the network structures corresponding to critical dates in sovereign debt markets in the recent past. We will present two network graphs for each episode: SCDS return networks before and after an important economic event ${ }^{19}$ In this section, we increase the number of SCDSs in the analysis by including the sovereigns which have full data availability for the relevant rolling window but not for the whole sample. We will present the number of sovereigns included explicitly in our graphs.

\footnotetext{
${ }^{19}$ We have done the analyses for four distinct events (in addition to the ones discussed here, we analyzed J.P. Morgan's takeover of Bear Stearns in March 2008 and the announcement of TARP in October 2008, a couple of weeks after the Lehman bankruptcy) and also looked at the same graphs for volatilities. To be concise, we omit these analyses from the paper.
} 
The readers should keep in mind some important details while analyzing the network graphs. First, we determine the cut-off points for node colors from our dynamic analysis of 38 countries from 2009 to 2013. Therefore, as long as the number of sovereigns are kept constant across network graphs, same node colors in two network graphs would imply similar levels of 'to connectedness.' However, the 'to connectedness' measures are no longer comparable across networks with different samples of sovereigns. To give an example, including New Zealand in the sample of sovereigns would affect the connectedness measures of Australia significantly. Although one can still make rough comparisons across graphs using the colors of nodes, the readers should keep in mind the possibility of deviations. Second, as the number of countries change, we are forced to use different scales to present the graphs in a visually coherent way. We will present the Gephi scale measures for the graphs. Distances across graphs, node sizes and edge thicknesses are only comparable when the scales for the two graphs are identical.

\subsubsection{Bernanke's July 19, 2013 Press Conference and the Taper Tantrum}

We analyze important events in a reverse chronological order and begin with the Bernanke speech. Figures 5(a) and 5(b) correspond to the return connectedness of 49 sovereigns in June 19 and June 20, respectively. Primary US stock indices fell more than $1 \%$ after the Bernanke speech on June 19, 2013. We would like to know which sovereigns were the main propagators of the return shock among SCDSs and which ones were on the receiving end.

A look at Figures 5(a) and 5(b) shows how the graph is compressed overall with the increasing gravitational force resulting from greater connectedness. US is noticeably disconnected from the rest of the SCDS return network. ${ }^{20}$ Moreover, the graph shows Eurozone core and periphery are not particularly affected by the speech. On the other hand, the local community structure of the Latin American and Asian countries starts to disappear as all the developing countries become more connected. South Africa experiences the biggest increase in its 'to connectedness' with 33\%. South Africa is followed by Eastern European countries (particularly Poland, Latvia and Hungary). We also see a comparable increase in New Zealand and Australia's 'to connectedness'.

\footnotetext{
20 This observation might sound counter-intuitive to the readers, however it is important to observe that even if the initial shock is originated in the US, it does not necessarily have any immediate implication for the US government's credit risk. To the contrary, as shocks originating from the US financial markets might affect the cost of borrowing or availability of funds for emerging market governments these countries are the likely transmitters of SCDS return shocks to other countries. We will discuss this topic in detail in the next section.
} 


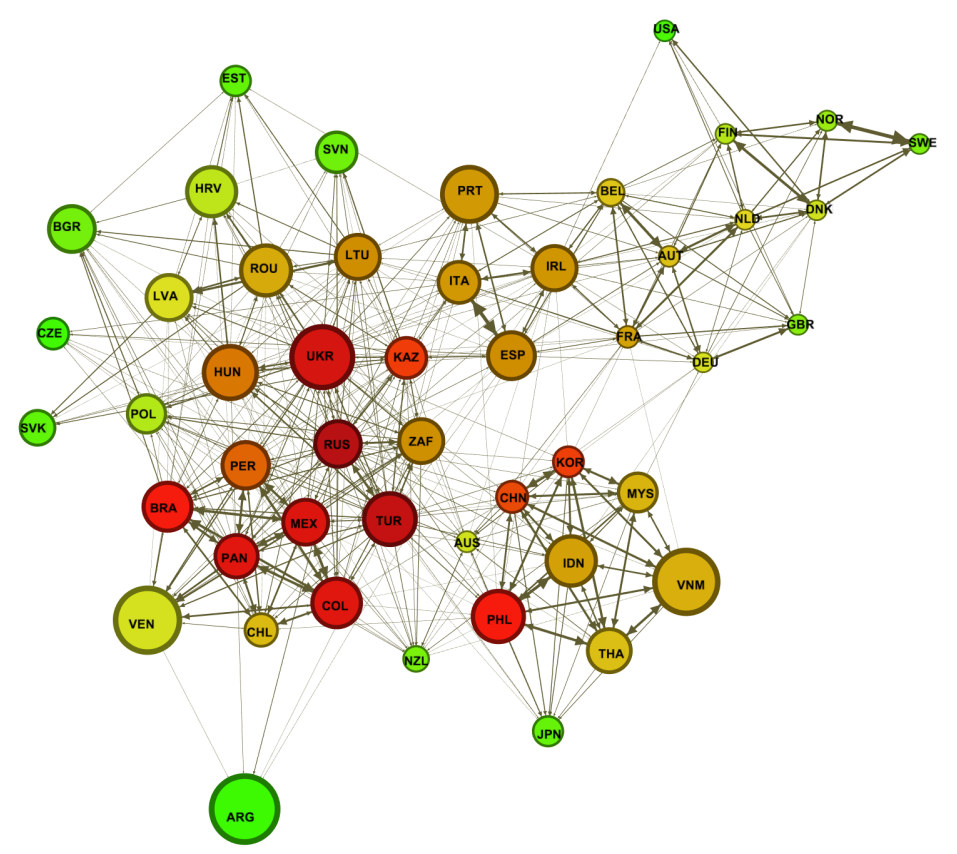

(a) June 19, 2013

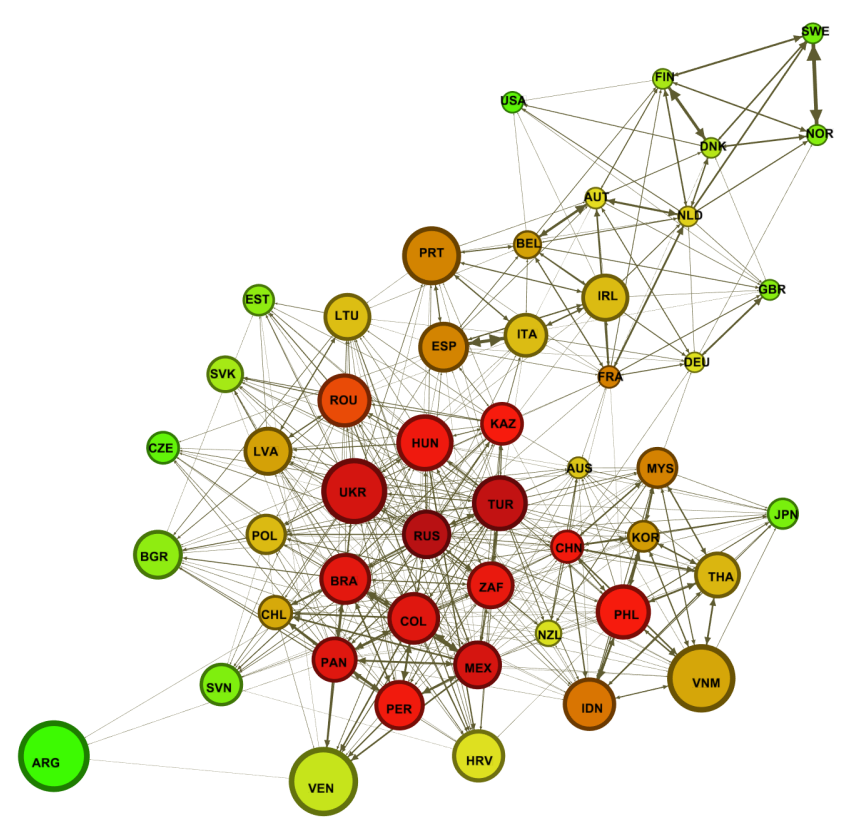

(b) June 20, 2013

Figure 5: Return Connectedness of 49 Sovereigns Before and After Bernanke's Speech, Scale $=120$ 
Bernanke's speech was expected to hit the emerging markets. Escalation in the propagation volumes of these developing countries as well as in Russia, Turkey and Brazil are not surprising. However, at the receiving end of the shocks, a completely different picture appears. Countries such as Bulgaria, Czech Republic and Estonia who have seen relatively modest increases in their 'to connectedness' measures (as well as Slovakia), experience the biggest increase in their 'from connectedness' measures. Japan is another big receiver of the shocks although it has one of the lowest 'to connectedness' measures in the whole sample. This event divides the sovereigns as receivers and transmitters of return shocks.

\subsubsection{First Greek Bailout}

We continue our analysis of network structures on some critical dates with the EU's first Greek bailout agreement on May 3, 2010, and the developments immediately after. The first Greek bailout episode is important because it has proven that the problems of the Greek economy were structural and it would take years to solve them. Furthermore, this episode has also proven that Greece's fiscal problems can turn into a potentially contagious sovereign debt crisis in the EU periphery. In Figures 6(a) and 6(b) we present CDS return connectedness for 50 sovereigns on May 3 and May 10, 2010 to analyze how the network structure changed within one week.

On both May 3 and May 10 (Figures 6(a) and 6(b), respectively) we can easily spot four main clusters. Latin American countries are on the upper side, East Asian countries are on the left, European countries on the right and the remaining developing countries are in the middle. The within-cluster connectedness of the East Asian countries is relatively low, as indicated by thin arrows among their respective nodes. The East Asian cluster is located closer to the other developing country cluster, yet they are mostly on the receiving end, as

indicated by the green and yellow color of their respective nodes. On the other hand they have considerable ties with Russia-Turkey-South Africa (RST) triangle.

with the exception of Post-Soviet states and Israel, sovereigns in the central developing country cluster are highly connected with each other and with countries in other clusters. With the exception of Argentina, Chile and Venezuela, Latin American countries have the highest connectedness with each other, but altogether they are weakly connected to other clusters. A similar structure exists for the European core. However, PIIGS countries (especially Greece, Italy and Ireland) stay on the periphery of the cluster, relatively more connected to the developing countries, with high 'to connectedness.' Obviously, Greece was in the midst of bailout talks. Domestic unrest definitely increased the pressure on Greek 


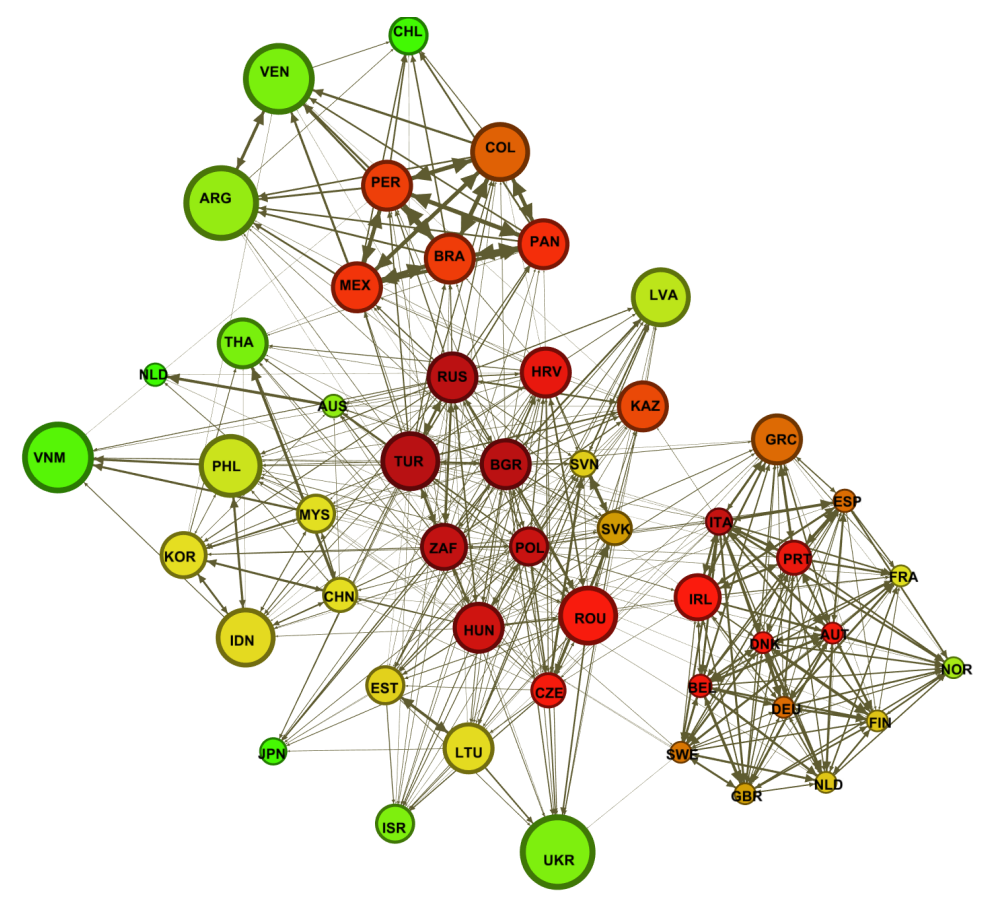

(a) May 32010

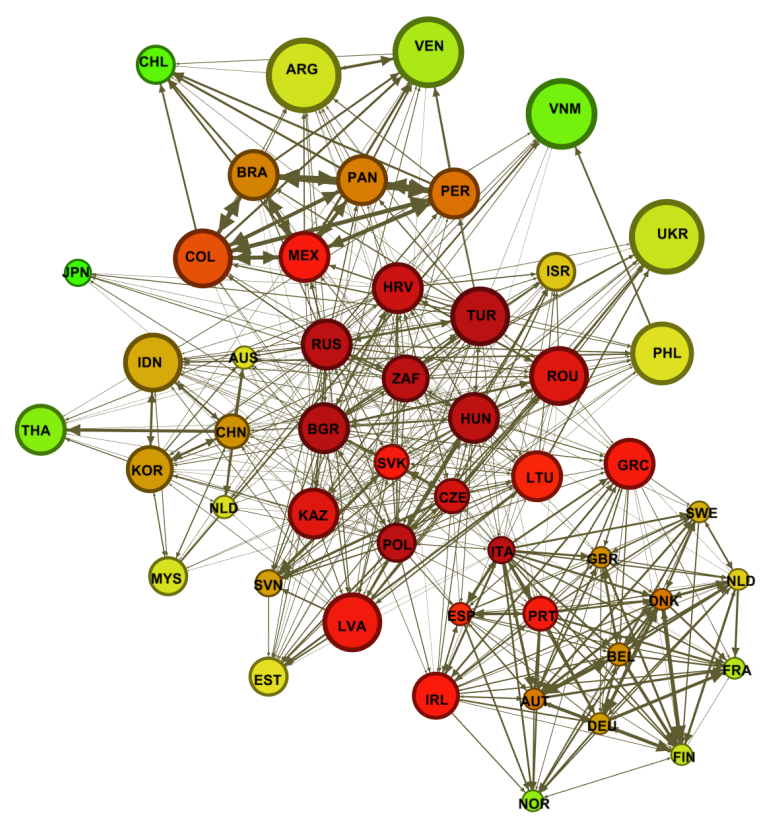

(b) May 102010

Figure 6: Return Connectedness of 50 SCDSs during the Greek Crisis, Scale $=150$ 
sovereign debt and hence increase the 'to connectedness' of the Greek SCDS returns. Italy that had the highest public sector debt to GDP ratio was also affected from the unfolding of the events in the Greek debt crisis. It was located the closest to the developing country cluster. Another equally important factor behind the high "to connectedness" of the Italian SCDS returns during the Greek debt debacle was the heavy exposition of Italian banks to the Greek government debt.

Both Portugal and Ireland are located closer to the developing country cluster with relatively high 'to connectedness.' At the time, Ireland was still reeling from the burden of the housing bubble burst and bank bailouts by the government in 2008. Portugal, on the other hand, had announced a new austerity plan with new budget cuts and privatization agendas two months before. Moreover, S\&P had downgraded Portugal's credit rating in mid-April 2010. Finally, the 'to connectedness' of Spain increased significantly as the Greek bailout efforts faced substantial domestic opposition from May 3 to May 10. Spain already suffered significant contraction in 2009 and 2010 following the burst of its real estate bubble in 2008, which also led to bankruptcies in its banking sector.

After the bailout agreement on May 3 and the ensuing country-wide protests in Greece, on May 10 we clearly see the increase in overall connectedness both within each cluster and across four clusters. All three, but especially, the European developed country cluster are drawn close to the main developing country cluster at the center. In addition, the total 'to connectedness' of the countries in the central developing country cluster turn to red and crimson red.

Mexico, among Latin American countries and China, among East Asian countries particularly move closer to the central developing country cluster. Greece moves away from the EU cluster and approaches to the eastern European countries. Slovenia loses its central place as Lithuania and Latvia move to more central positions. From May 3 to May 10, the biggest increases in the 'to connectedness' measure occur in the cases of Latvia and Lithuania with $60 \%$ and $40 \%$ respectively. Moreover, neither country experiences a significant increase in its ties with any particular country. Both countries transmit the return shock originated in the Eurozone to sample countries rather uniformly.

We also see that Israel and New Zealand (which are generally disconnected from the graphs at other periods) have their 'to connectedness' increased in that week. China and South Korea see big increases in their 'to connectedness' while central EU countries lose their transmitting power with the unfolded events. China transmits the shock to Australia 
and New Zealand as well as to the East Asian cluster ${ }^{21}$.

Finally, Greece experiences a modest increase with 15\%, although it is the originator of the shock. RST triangle, Italy and Bulgaria are the biggest transmitters of shock on both days. All countries see an increase in their 'from connectedness'. On the other hand, New Zealand experiences the biggest increase in its 'from connectedness' after the events with $17 \%$. New Zealand is followed by Argentina, Vietnam, Israel, Venezuela, Ukraine and Latvia. Actually, these were the most disconnected sovereigns in our sample and they were rarely influenced by the outside shocks in other sample periods. EU crisis was the most global crisis in our sample period in that sense.

\section{Implications for the Determinants of Soverign credit risk}

So far we analyzed the static and dynamic connectedness of SCDS return and volatilities from 2009 to 2014. The results are intriguing by themselves and implications of each daily network and dynamic pairwise connectedness can be separately analyzed to draw conclusions. It is impossible to analyze them all in a dozen papers, let alone one paper. However, we will try to present the general implications from our analysis in this section, focusing on the determinants of sovereign credit risk. For each result, we will present our findings, compare them with previous findings in the literature and provide justification for the discrepancies.

I-1: Global factors are more important in determination of SCDS spreads, even more in times of crisis

We have seen in the dynamic estimation that the system-wide connectedness index, a measure of the effect of global factors, is above $65 \%$ for returns and above $50 \%$ for volatilities, throughout the sample period. In Table 1 we present the average, minimum and maximum effects of global factors (in percentage points) on our sample of sovereigns over the period from 2009 to 2014.

These correspond to 'from connectedness' measures in our connectedness analysis. The effect of global factors on each of the 38 sovereigns, as measured by the 'from connectedness,'

${ }^{21}$ However, we do not observe a significant effect of China on European countries. The 'relationship' reported by Ang and Longstaff (2013) does not lead to a causal inference in a setting where a large number of SCDSs are controlled for. 
Table 1: Global Factors in SCDS Spread Movements (09/2009 - 04/2014)

\begin{tabular}{|c|c|c|c|c|c|c|c|c|}
\hline \multirow[b]{2}{*}{ Sovereigns } & \multicolumn{4}{|c|}{ Returns } & \multicolumn{4}{|c|}{ Log Return Volatilities } \\
\hline & $\begin{array}{l}\text { Avg } \\
(\%)\end{array}$ & $\begin{array}{l}\text { Min } \\
(\%)\end{array}$ & $\begin{array}{l}\operatorname{Max} \\
(\%)\end{array}$ & $\begin{array}{l}\text { Avg Spread } \\
\text { (BPS) }\end{array}$ & $\begin{array}{l}\text { Avg } \\
(\%)\end{array}$ & $\begin{array}{l}\text { Min } \\
(\%)\end{array}$ & $\begin{array}{l}\operatorname{Max} \\
(\%)\end{array}$ & $\begin{array}{l}\text { Avg Vol. } \\
\left(10^{\wedge}-3\right)\end{array}$ \\
\hline Argentina & 76.8 & 31.4 & 93.4 & 1346.6 & 75.7 & 32.8 & 93.4 & 1.4 \\
\hline Brazil & 90.7 & 80.7 & 97.7 & 137.5 & 85.2 & 76.7 & 91.7 & 0.8 \\
\hline Chile & 84.8 & 48.9 & 98.6 & 86.1 & 76.0 & 47.2 & 91.1 & 2.0 \\
\hline Colombia & 90.8 & 82.0 & 97.5 & 126.0 & 83.8 & 73.1 & 92.4 & 0.8 \\
\hline Mexico & 90.9 & 83.2 & 98.2 & 119.9 & 83.8 & 74.9 & 90.9 & 0.9 \\
\hline Panama & 90.3 & 80.4 & 97.7 & 118.5 & 82.9 & 72.5 & 92.4 & 1.1 \\
\hline Peru & 88.4 & 59.4 & 97.6 & 128.6 & 81.9 & 65.9 & 93.2 & 0.9 \\
\hline Venezuela & 82.5 & 61.3 & 91.8 & 992.4 & 73.3 & 42.0 & 91.5 & 0.9 \\
\hline South.Africa & 90.5 & 72.9 & 99.4 & 162.4 & 84.5 & 57.9 & 93.1 & 0.8 \\
\hline Bulgaria & 87.6 & 52.8 & 95.0 & 219.4 & 83.8 & 57.4 & 93.1 & 0.9 \\
\hline Croatia & 88.0 & 60.8 & 95.3 & 325.5 & 84.0 & 57.3 & 91.7 & 0.6 \\
\hline Czech.Republic & 82.2 & 15.7 & 94.1 & 89.8 & 79.3 & 38.9 & 91.7 & 0.8 \\
\hline Hungary & 89.4 & 75.3 & 94.6 & 343.2 & 83.3 & 60.8 & 93.7 & 0.6 \\
\hline Kazakhstan & 88.7 & 63.1 & 99.1 & 196.3 & 79.6 & 39.5 & 94.3 & 1.4 \\
\hline Latvia & 80.3 & 21.5 & 94.6 & 256.2 & 77.9 & 26.6 & 93.1 & 0.8 \\
\hline Lithuania & 81.8 & 25.9 & 99.2 & 218.8 & 73.6 & 20.7 & 92.2 & 2.0 \\
\hline Poland & 88.1 & 58.6 & 95.5 & 140.7 & 83.5 & 62.6 & 92.7 & 0.8 \\
\hline Romania & 88.8 & 64.5 & 95.0 & 280.7 & 79.4 & 35.8 & 93.0 & 0.9 \\
\hline Russia & 91.6 & 80.3 & 98.8 & 175.3 & 84.6 & 52.9 & 92.9 & 1.1 \\
\hline Slovakia & 82.6 & 34.2 & 96.8 & 122.2 & 73.4 & 39.4 & 90.1 & 0.9 \\
\hline Slovenia & 77.6 & 32.9 & 98.2 & 218.9 & 69.8 & 24.0 & 89.8 & 0.9 \\
\hline Turkey & 91.5 & 81.7 & 98.6 & 191.5 & 85.6 & 61.5 & 92.3 & 0.8 \\
\hline Ukraine & 83.7 & 36.7 & 98.4 & 741.5 & 73.0 & 19.3 & 91.5 & 0.9 \\
\hline Austria & 86.1 & 51.4 & 94.8 & 83.6 & 81.6 & 37.4 & 90.2 & 0.6 \\
\hline Belgium & 87.4 & 58.3 & 94.9 & 132.4 & 80.5 & 34.7 & 92.4 & 0.8 \\
\hline Denmark & 83.9 & 52.4 & 94.6 & 53.7 & 77.7 & 38.5 & 92.8 & 0.6 \\
\hline Finland & 83.7 & 49.3 & 94.5 & 38.2 & 79.0 & 61.0 & 90.3 & 1.4 \\
\hline France & 86.2 & 65.5 & 94.7 & 97.4 & 77.8 & 43.3 & 91.1 & 0.8 \\
\hline Germany & 84.6 & 38.7 & 94.8 & 48.4 & 80.5 & 46.3 & 90.1 & 2.0 \\
\hline Ireland & 86.2 & 56.9 & 93.2 & 374.4 & 80.5 & 51.1 & 90.7 & 0.8 \\
\hline Italy & 89.4 & 72.2 & 94.4 & 258.9 & 81.9 & 35.6 & 91.3 & 0.9 \\
\hline Japan & 68.8 & 34.4 & 95.0 & 79.9 & 57.0 & 16.7 & 86.9 & 1.1 \\
\hline Netherlands & 85.4 & 51.0 & 94.2 & 58.4 & 79.7 & 36.0 & 90.9 & 0.9 \\
\hline Norway & 78.0 & 50.4 & 92.6 & 23.0 & 76.3 & 52.7 & 91.5 & 0.9 \\
\hline Portugal & 84.5 & 53.7 & 95.2 & 539.7 & 70.9 & 19.8 & 87.1 & 0.8 \\
\hline Spain & 88.2 & 68.9 & 94.5 & 273.4 & 80.1 & 35.8 & 90.9 & 0.9 \\
\hline Sweden & 80.4 & 43.2 & 97.2 & 35.8 & 77.5 & 49.7 & 90.9 & 0.6 \\
\hline United.Kingdom & 82.9 & 53.2 & 94.9 & 59.3 & 77.8 & 22.1 & 91.8 & 0.8 \\
\hline
\end{tabular}


are above $68 \%$ in our sample for SCDS returns and above $56 \%$ for return volatilities, averaging over time. However, for 12 of 38 sovereigns, the effect of global factors on SCDS returns drop below $50 \%$ at least once and for 23 of 38 sovereigns effect of global factors on SCDS return volatilities drop below $50 \%$ at least once. It is trivial to subtract these measures from $100 \%$ and get the percentage of domestic factors on credit risk. ${ }^{22}$

Some studies go further and analyze relative effects of different indicators of idiosyncratic and global shocks. Ang and Longstaff (2013), Longstaff et al. (2011), Beirne and Fratzscher (2013) and Heinz and Sun (2014) divide these indicators into three: macroeconomic fundamentals, global risk aversion and liquidity risk. They treat macroeconomic fundamentals as domestic indicators while treating the indicators related to the other two as global indicators.

There are several problems with this approach. First, they do not explicitly control for the global effects. They control for macroeconomic fundamentals and attribute the unexplained part in their model to global financial effects or 'contagion.' However, global financial effects are quite possibly correlated with macroeconomic fundamentals. Excluding global factors would cause an overestimation of the role of macroeconomic fundamentals. Second, macroeconomic fundamentals are monthly, if not less frequent. Therefore, the whole analysis needs to be conducted on a monthly or quarterly frequency. Precision of the estimates go down with the number of observations while considerable amount of information is lost. Third, one cannot treat macroeconomic fundamentals as domestic, given that they are largely affected by global indicators as well. Moreover, changes in liquidity and risk aversion are also affected by domestic shocks. Thus, this kind of a division does not give us the degree of connectedness or vulnerability of a sovereign to global shocks.

Lastly, these regressions suffer from serious simultaneity problems. These factors affect SCDS spreads but the spreads also affect them. SCDSs are important assets which are closely followed by investors around the world. An increase in SCDS spreads would surely increase global risk aversion of the investors directly. The liquidity of these swaps also directly depends on their spreads. Although it is less intuitive, it can be argued that level of spreads also has effects on macroeconomic fundamentals. A change in market's view of the riskiness of a sovereign's bonds would have effects over the yields of these bonds and the sovereign's access to credit markets. ${ }^{23}$ Most important of all, these studies include regional

\footnotetext{
22 These measures indicate a much larger systemic risk (risk resulting from global factors) percentage compared to Ang and Longstaff (2013). This discrepancy is expected since they are using only 11 Eurozone countries to account for the systemic part of the risk.

23 The effect on macroeconomic fundamentals is more severe in D'Agostino and Ehrmann (2013) and Heinz and Sun (2014) since they are using expectations on future macroeconomic fundamentals instead of already measured levels.
} 


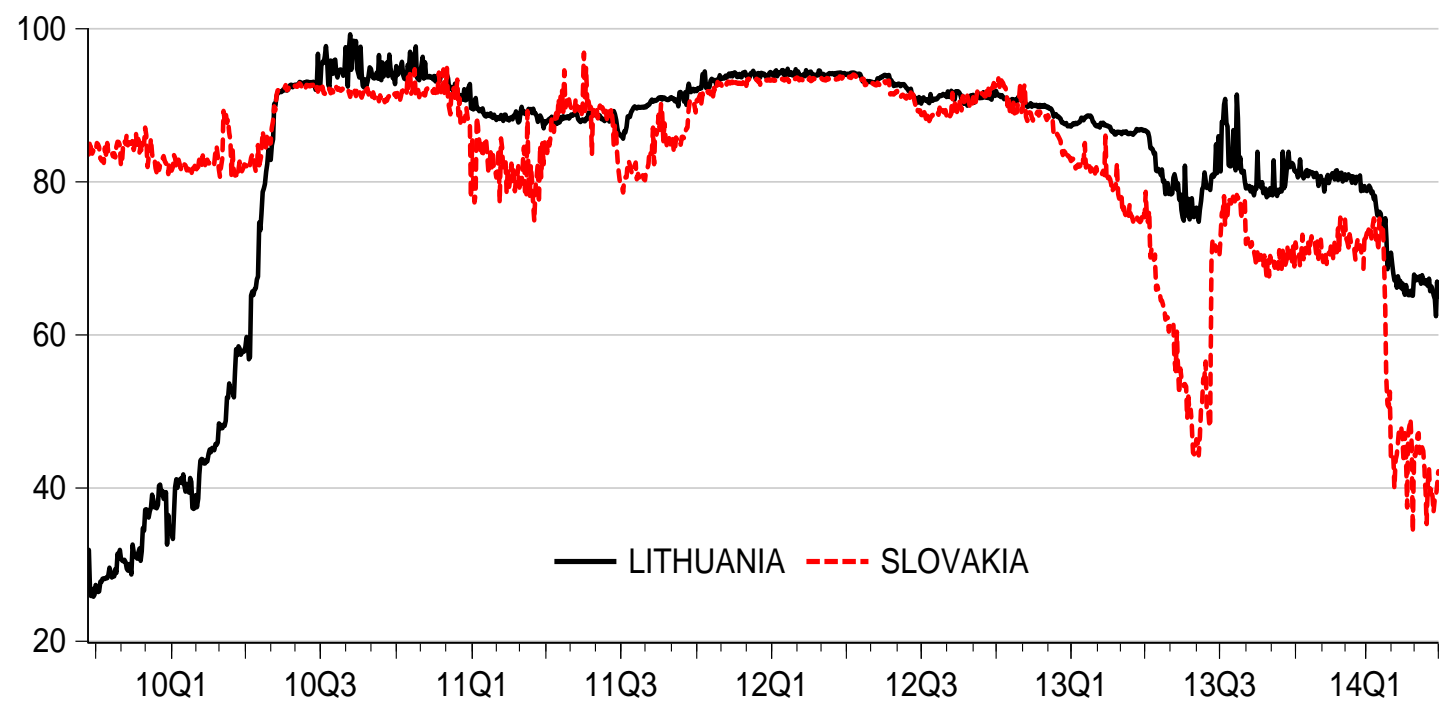

Figure 7: 'From connectedness' of Lithuania and Slovakia, 2009-2014

spreads as an exogenous variable. Beirne and Fratzscher (2013) even claim "... it does not seem plausible that such effects materialize immediately, within the same month." although they accept a simultaneity is present in their model. We have shown that SCDS spreads do effect each other in a single day. Therefore, using their methodology, one cannot get unbiased coefficients to comment on. Our VAR framework at least acknowledges the simultaneity and uses the lags of variables to minimize the bias.

\section{I-2: Connectedness of sovereign credit risk across the globe change substantially over time}

In Figures 3 and 4 we have seen how the total connectedness measures change over time sample period. We have already presented the main results in the previous section. Global factors become more important in times of turmoil. The importance of global factors can be as high as $99.5 \%$ for some sovereigns where the auto-regressive structure of SCDS returns would not be able to explain anything. For example, as of April 2014, the global factors are able to explain a mere $20 \%$ of the variation in Czech Republic's SCDS returns. However, this value is around 90\% throughout the heated periods of European sovereign debt crisis.

To illustrate, in Figure 7, we present two series: The dashed line corresponds to the 'from connectedness' of Lithuania while the solid line corresponds to the 'from connectedness' of Slovakia. In 2009, the percent share of the global factors in the determination of Slovakia's SCDS returns was nearly three times the corresponding figure for Lithuania. After the Greek protests of the first bailout package in May 2010, Lithuania's 'from connectedness' 
has surpassed that of Slovakia's. The two series were indistinguishable for most of the crisis periods. The importance of global factors for Slovakia has seen a big fall following the relief in the markets beginning in 2013. Both sovereigns have experienced a significant increase in their 'from connectedness' with Bernanke's speech. As of April 2014, Lithuania's 'from connectedness' is twice as high as that of Slovakia's.

Let us try to make sense of it. Slovakia became a new member of the Eurozone in the beginning of 2009. Before the membership, adoption of Euro was seen as a big advantage, considering the drop in the exchange rate risk for borrowing, a more reliable monetary policy and easier international commercial transactions. Euro crisis, however, has been a bitter surprise for the Slovak economy. Monetary stability has become a disadvantage instead of an advantage and borrowing has become more difficult due to high risk pertaining to Eurozone. However, Slovakia's recovery was successful and faster than Estonia and Slovenia, which have similar economic structures. Slovakia has a high unemployment and a modest growth, but also has a strong banking sector (a probable barrier against contagion), which causes Slovakian sovereign credit risk to be more related with domestic factors as of 2014 . Lithuania, on the other hand, was one of the last sovereigns to be hit by the crisis with high growth rates until 2009. In 2009, Lithuania's economy has shrunk by $15 \%$. After a devastating year, however, Lithuania managed to grow by $3.5 \%$ on average. After the crisis, Lithuania delayed its plan to join the Eurozone. Lithuania was scheduled to be a member of the Eurozone at the beginning of 2015 yet the health of Eurozone was being questioned lately. There was ambiguity over whether the membership could create unnecessary ties with the Eurozone countries and inability to deal with possible problems following the loss of monetary policy independence. Therefore, Lithuania was still (as of March 2014) highly influenced by outside shocks, mostly the ones created by European countries.

I-3: Global stock market indices, exchange rate movements and bond returns generate little connectedness to $S C D S$ returns

Shocks to either real or financial sectors of a country carry the potential to have direct effects on government budgets. A decline in industrial growth decreases tax income due to decrease in demand, investment and production. Moreover, governments generally use fiscal stimuli to get the economy out of a slump. Increased problems in the financial sector has the potential to lower the industrial growth through lending cuts. Furthermore, the possibility of bank bailouts creates additional burden on government budget and make it more difficult to sustain the sovereign debt. 
Countries' financial and real sectors are also tightly connected through multiple trade and financial channels. A slowing Chinese economy would definitely affect the world oil price and hence the credit risks of Russia and Venezuela, as these governments' revenues depend heavily on oil export revenues. The main question for global indices then becomes do sovereigns immediately respond to shocks in real and financial sectors of other sovereigns, or does the response come after the effects of these shocks are reflected in the CDS spreads of the sovereign where the shocks are originated from. If the latter statement is true, global indices would not add more explanatory power to the simple VAR analysis with only SCDSs.

There are also shocks that are not concretely related to other sovereigns. For example, a shock in the financial sector of Lithuania would not have direct effect on the banking sector of Turkey. Many of the shocks are in this category for many sovereigns. We argue that, especially for these kind of shocks, the analysts are more interested in the reactions of the originator and the affected sovereigns' credit risk. Therefore, controlling for the SCDSs of these sovereigns would suffice. These arguments are intuitively appealing, however, lead to strong claims and need to be backed by quantitative results.

Several papers (such as Longstaff et al. (2011), Alter and Beyer (2014), Heinz and Sun (2014)) use indices and variables regarding real and financial sectors of individual and groups of sovereigns to explain changes in SCDS spreads. The individual variables include S\&P 500, Dow Jones Industrial Average and the TED spread, while aggregate variables include Euro Stoxx 50, iTraxx Crossover and VIX indices. We find that, as long as the sovereigns - data of which is used in the calculation of these indices - are properly accounted for in the regressions (which include only SCDS returns), these extra variables add little to the analysis.

We check for primary stock indices, exchange rates and five year bond yields for as many countries as we can find to see if the return shocks to these asset classes can explain more than what is already explained by SCDS returns. For the interest of time and space, we undertake the connectedness analysis over asset returns over the full-sample period. We bring 58 stock market indices, 28 exchange rates and 27 sovereign bonds anew ${ }^{24}$, in addition to the 38 SCDSs we had. We also present only the top $5 \%$ of the existing edges in this section in order to be able to view and interpret the overcrowded graph without causing any change in the results. The node sizes of primary indices, exchange rates and bonds are all the same and equal to the average node size of SCDSs.

\footnotetext{
${ }^{24}$ We originally had 162 total nodes. However, primary stock market indices of Venezuela, Bosnia, Sri Lanka and Zambia, exchange rates of Pakistan, China and Ukraine and bonds of Malaysia, Philippines, India and Sri Lanka were extremely disconnected from the rest of the graph. To present a visually accessible graph, we dropped those from the sample.
} 


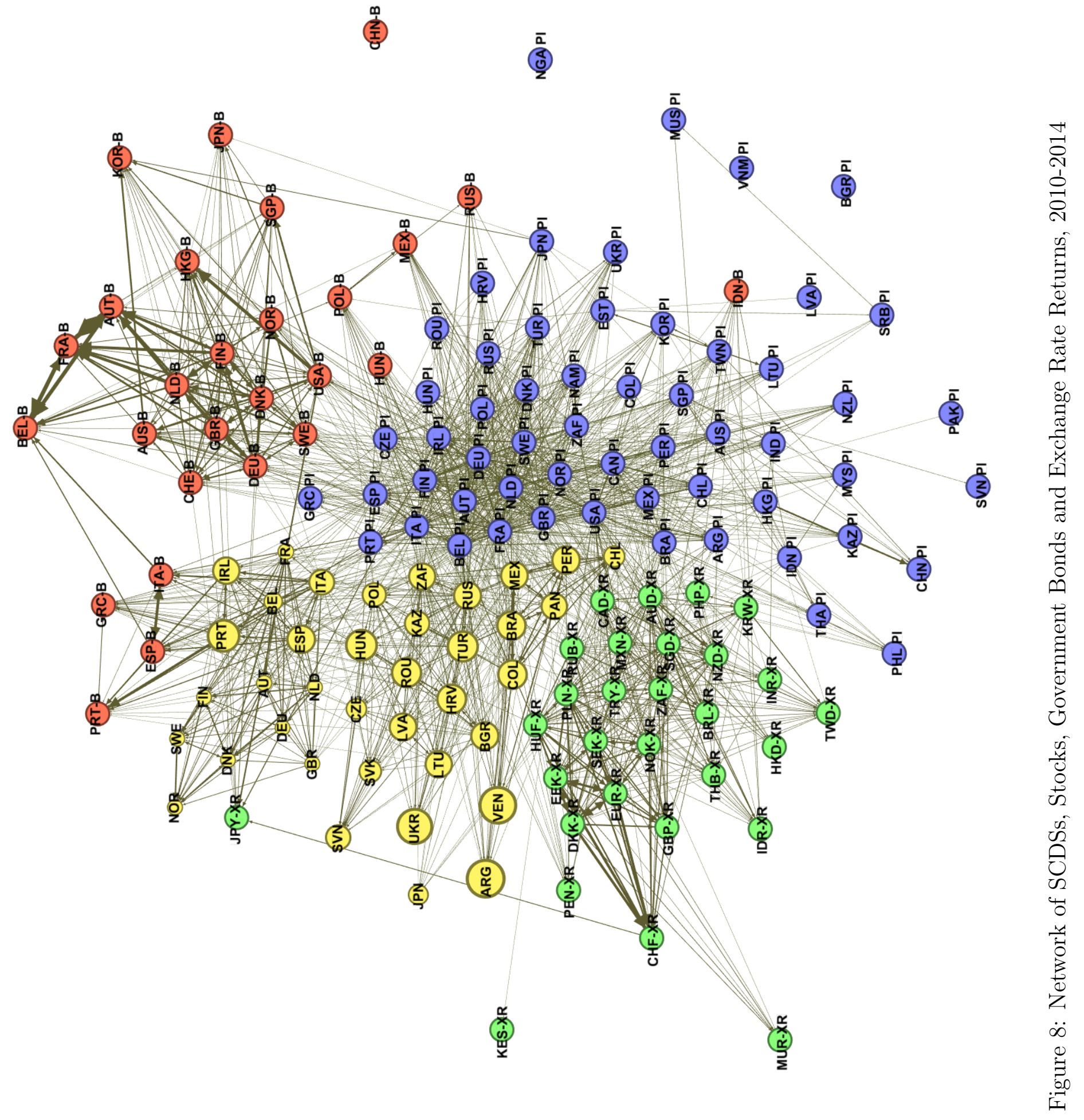


In Figure 8, SCDSs (yellow nodes), primary stock indices (blue nodes), exchange rates (green nodes) and bonds (red nodes) form mutually exclusive clusters with a few exceptions. ${ }^{25}$ Moreover, the number of edges inside the clusters are considerably larger than the edges between the clusters. Each of these clusters have important implications but we will focus on the parts that are important for the analysis of SCDSs.

SCDSs and government bond returns of Eurozone periphery have high regional connectedness while a similar observation cannot be made for other country groups. This could imply that bond prices of these sovereigns would improve our estimation. However, the direction of the connectedness is mostly from SCDSs to bonds. The primary indices does not have particularly strong ties with SCDSs. Interestingly, the primary indices of the developed countries and SCDSs of the emerging markets are the closest among these two clusters, but the primary stock market index for the US (S\&P 500) does not have a particular importance in terms of determining spreads of SCDSs, contrary to the claims made in the literature. Lastly, exchange rates have very little connection to the SCDS cluster (with the exception of Japanese Yen, the biggest edge of which is with US bond prices). We do not claim that SCDSs internalize all the information stored in other assets. However, it is clear that these additional assets do not have any central role in determination of SCDS spreads. Moreover, we still see the same clustering structure for the SCDSs as we did in our main analysis. The same result can be observed even when we include these extra asset classes one by one. Therefore, an analyst would better spend her time studying and understanding the behavior of SCDSs of connected countries instead of following other financial asset returns in those countries.

These results do not imply there is no relation or correlation between global indices and SCDS spreads. Therefore, these findings are not inconsistent with the results reported by Longstaff et al. (2011) or Ang and Longstaff (2013). We merely improve on the basic comments made by these papers and give a comprehensive analysis which shows there is no convincing causal mechanism that functions between SCDSs and global stock market indices when a large sample of SCDSs are accounted for. ${ }^{26}$

\footnotetext{
${ }^{25}$ For this graph in particular, we drop the graphical display convention of representing 'to connectedness' with node color. Since the graph is very large and our main aim is observing the main patterns, we use it to differentiate asset classes.

${ }^{26}$ Longstaff et al. (2011) data set includes 26 SCDSs. At first, it might seem their coverage is not very narrow compared to our analysis. However, in their regressions, they only include a regional and a global average of other SCDS spreads. Moreover, due to possible endogeneity issues they end up instrumenting them with other variables. Thus, basically in their analysis for the determinants of SCDS spreads they are not fully controlling for SCDS spreads in other countries.
} 
Finally, Figure 8 provide further support to Diebold and Yilmaz (2015) who showed that when major asset classes for four major industrial economies (the U.S., UK, the EU and Japan) are considered, the connectedness took place mostly within the same asset class and across countries. The clustering of four asset class returns in Figure 8 show that asset return shocks mostly affect returns of the the same assets in other countries rather than the returns of other assets in the same country or in other countries. A very neat example of this relations was revealed during the U.S. financial crisis. While the U.S. stock market was hit by both return and volatility shocks, the government bond market was viewed as a safe haven where investors flock to preserve the value of their portfolios. Similarly, the returns to U.S. sovereign CDS and the U.S. dollar were not affected much from the return and volatility shocks that hit the U.S. stock markets.

I-4: The main drivers of global sovereign risk movements are emerging market countries

The EU sovereign debt and banking crisis had started in late 2009 and lasted close to four years. Financial markets around the world carefully watched the events as they unfolded, while critics debated whether Eurozone could survive a crisis of that proportion. It was argued that a single default in EU could trigger a chain of defaults. Therefore, EU core countries continuously produced bailout packages one after another to keep the problematic countries afloat. Despite the full focus on the Eurozone countries, our analysis shows that the emerging market economies were the main propagators of sovereign risk shocks around the globe.

In order to substantiate this finding, we next present the mean, minimum and maximum return and volatility 'to connectedness' measures for all countries in Table 2 along with the average SCDS spreads and return volatilities. Troubled EU members (Ireland, Portugal, Spain and Italy) were relatively more important transmitters of credit risk shocks compared to other developed countries, but they were significantly behind the emerging markets. Turkey and Russia were the main transmitter of sovereign credit risk shocks on average, closely followed by South Africa, Mexico, Brazil and Colombia. On the other hand, Argentina and Venezuela, the most problematic countries of the last decade in terms of sovereign credit risk, were well behind these countries in terms of transmitting sovereign credit risk shocks to others. These results are valid whether we measure the connectedness of SCDS returns or volatilities. 
Table 2: Contribution to Global Sovereign credit risk (09/2009 - 04/2014)

\begin{tabular}{|c|c|c|c|c|c|c|c|c|}
\hline \multirow[b]{2}{*}{ Sovereigns } & \multicolumn{4}{|c|}{ Returns } & \multicolumn{4}{|c|}{ Log Return Volatilities } \\
\hline & $\begin{array}{l}\text { Avg } \\
(\%)\end{array}$ & $\begin{array}{l}\text { Min } \\
(\%)\end{array}$ & $\begin{array}{l}\operatorname{Max} \\
(\%)\end{array}$ & $\begin{array}{l}\text { Avg Spread } \\
\text { (BPS) }\end{array}$ & $\begin{array}{l}\text { Avg } \\
(\%)\end{array}$ & $\begin{array}{l}\text { Min } \\
(\%)\end{array}$ & $\begin{array}{l}\operatorname{Max} \\
(\%)\end{array}$ & $\begin{array}{l}\text { Avg Vol. } \\
\left(10^{-3}\right)\end{array}$ \\
\hline Argentina & 52.8 & 7.9 & 97.9 & 1346.6 & 40.1 & 6.7 & 89.5 & 1.4 \\
\hline Brazil & 114.6 & 68.0 & 138.0 & 137.5 & 94.0 & 52.0 & 120.7 & 0.8 \\
\hline Chile & 65.7 & 10.8 & 102.2 & 86.1 & 42.2 & 13.5 & 68.2 & 2.0 \\
\hline Colombia & 113.7 & 62.7 & 143.1 & 126.0 & 88.8 & 59.4 & 113.3 & 0.8 \\
\hline Mexico & 114.5 & 60.6 & 140.7 & 119.9 & 89.7 & 50.3 & 116.7 & 0.9 \\
\hline Panama & 107.3 & 60.6 & 135.2 & 118.5 & 81.4 & 45.1 & 122.8 & 1.1 \\
\hline Peru & 96.0 & 17.7 & 138.5 & 128.6 & 70.3 & 7.1 & 110.6 & 0.9 \\
\hline Venezuela & 56.6 & 19.4 & 89.3 & 992.4 & 40.2 & 16.0 & 78.8 & 0.9 \\
\hline South.Africa & 114.7 & 44.8 & 143.8 & 162.4 & 89.1 & 42.8 & 139.4 & 0.8 \\
\hline Bulgaria & 96.1 & 24.3 & 158.8 & 219.4 & 90.5 & 25.0 & 152.9 & 0.9 \\
\hline Croatia & 96.5 & 40.1 & 148.5 & 325.5 & 86.0 & 28.2 & 138.2 & 0.6 \\
\hline Czech.Republic & 68.9 & 7.7 & 152.8 & 89.8 & 73.7 & 17.7 & 136.9 & 0.8 \\
\hline Hungary & 102.6 & 62.1 & 145.0 & 343.2 & 86.1 & 41.6 & 137.7 & 0.6 \\
\hline Kazakhstan & 97.8 & 44.8 & 136.3 & 196.3 & 60.7 & 21.1 & 106.1 & 1.0 \\
\hline Latvia & 77.6 & 9.5 & 135.7 & 256.2 & 75.2 & 20.8 & 122.7 & 0.7 \\
\hline Lithuania & 74.1 & 10.4 & 120.3 & 218.8 & 69.4 & 13.2 & 117.9 & 0.5 \\
\hline Poland & 97.3 & 35.6 & 173.8 & 140.7 & 91.5 & 31.2 & 133.1 & 1.2 \\
\hline Romania & 101.3 & 47.6 & 156.9 & 280.7 & 74.3 & 19.4 & 148.1 & 0.6 \\
\hline Russia & 127.0 & 48.2 & 156.6 & 175.3 & 97.6 & 42.8 & 129.1 & 1.1 \\
\hline Slovakia & 59.0 & 14.0 & 126.5 & 122.2 & 57.5 & 14.9 & 90.5 & 1.7 \\
\hline Slovenia & 42.0 & 9.6 & 89.6 & 218.9 & 40.8 & 7.9 & 83.3 & 1.0 \\
\hline Turkey & 127.4 & 27.8 & 151.3 & 191.5 & 105.5 & 50.0 & 143.7 & 0.8 \\
\hline Ukraine & 76.5 & 11.2 & 136.2 & 741.5 & 55.0 & 11.7 & 99.8 & 1.1 \\
\hline Austria & 94.2 & 32.6 & 126.5 & 83.6 & 86.1 & 50.9 & 120.9 & 2.0 \\
\hline Belgium & 96.7 & 42.4 & 119.3 & 132.4 & 84.3 & 18.0 & 142.9 & 1.4 \\
\hline Denmark & 77.7 & 27.9 & 123.1 & 53.7 & 62.8 & 28.3 & 89.9 & 3.4 \\
\hline Finland & 74.3 & 28.5 & 104.0 & 38.2 & 75.1 & 32.2 & 138.0 & 3.1 \\
\hline France & 86.0 & 30.9 & 126.6 & 97.4 & 73.9 & 27.2 & 134.1 & 1.9 \\
\hline Germany & 84.8 & 19.6 & 116.6 & 48.4 & 78.1 & 48.3 & 119.4 & 2.0 \\
\hline Ireland & 78.5 & 35.8 & 135.7 & 374.4 & 74.7 & 40.0 & 103.2 & 0.8 \\
\hline Italy & 108.3 & 76.0 & 146.7 & 258.9 & 85.0 & 45.2 & 123.4 & 1.1 \\
\hline Japan & 22.8 & 5.6 & 58.8 & 79.9 & 19.4 & 5.9 & 48.0 & 0.7 \\
\hline Netherlands & 84.8 & 37.3 & 109.4 & 58.4 & 75.0 & 33.5 & 124.8 & 1.7 \\
\hline Norway & 46.3 & 26.0 & 72.3 & 23.0 & 60.3 & 25.6 & 99.0 & 5.4 \\
\hline Portugal & 75.2 & 17.0 & 138.0 & 539.7 & 54.4 & 4.2 & 96.2 & 1.3 \\
\hline Spain & 94.8 & 54.9 & 123.7 & 273.4 & 72.8 & 27.7 & 103.7 & 2.0 \\
\hline Sweden & 66.5 & 18.9 & 103.8 & 35.8 & 75.1 & 23.7 & 120.1 & 4.8 \\
\hline United.Kingdom & 74.9 & 28.4 & 127.5 & 59.3 & 73.2 & 13.8 & 136.8 & 1.8 \\
\hline
\end{tabular}




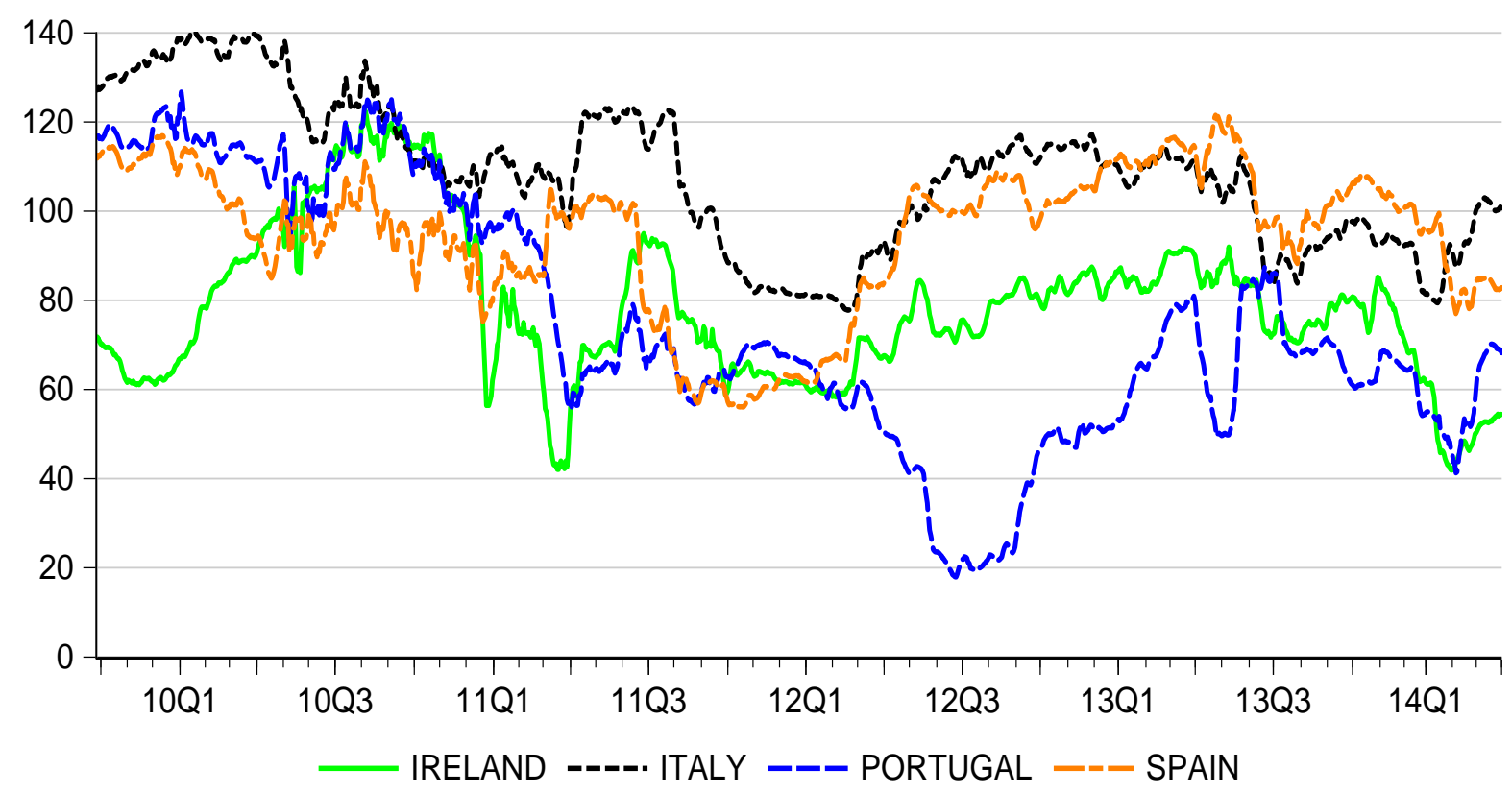

Figure 9: Directional SCDS Return Connectedness of Troubled EU Members "To Others"

I-5: Severely problematic countries cease to be important transmitters of sovereign credit risk shocks

There have always been sovereigns that experience near-defaults for rather long periods. The possibility of a contagion in case of a default or debt restructuring is a great source of fear among sovereigns. The cases of Russia in 1998, Argentina in 2005, Greece, Portugal and Ireland during the EU crisis were closely followed by global investors. Our findings show that return connectedness of severely problematic SCDSs tend to increase during the build up phase of a crisis. However, after the peak of the crisis, influence of the credit risk of severely problematic countries see a big drop and they cease to be major shock transmitters. From then onwards, any new rounds of shocks originating from these countries are transmitted not by themselves, but rather through other sovereigns that were most affected by the crisis.

In Figure 9 we present the 'to connectedness' of four countries' - Ireland, Italy, Portugal and Spain - SCDS returns between 2009 and 2014. These countries were affected significantly by the global financial crisis, to the point where EU bailout packages were considered and/or actually implemented. Therefore, these countries perfectly fit our description of severely problematic countries. In the graph, Italy, Spain and Portugal have large 'to connectedness' at the beginning of our sample. The high indebtedness of these countries was well known and 
led to skepticism among investors even before the beginning of the European crisis. On the other hand, Ireland was considered relatively safe, with debt levels significantly below the Eurozone average. However, due to the Irish government's decision to guarantee all deposits in Irish banks and the resulting bank bailouts, its debt to GDP ratio increased sharply to reach the highest level in the Eurozone by 2011. We can see that the 'to connectedness' of Ireland on other SCDS markets is lower compared to other three in late 2009 and early 2010, but it increases quickly to similar levels by the first Greek bailout package implemented in May 2010. During the protests and the following months, all four countries experience increases in their 'to connectedness' measures. However, after the 2010 Summer, these countries start to lose their influence in the markets. The 'to connectedness' of Ireland and Portugal (perhaps, viewed as more problematic than Italy and Spain) experience major drops and never turn back to the levels they reached at the end of 2010.

The effect of Ireland and Portugal on other SCDS markets have seen a further decrease around March 2011 as bailout talks reemerged. Spain and Italy did not experience sharp decreases as these countries were not perceived as problematic as Greece, Ireland and Portugal. Spain's 'to connectedness' increased again at the beginning of March 2011 as Spanish banks failed a stress test and Moody's downgraded Spain's credit rating. The 'to connectedness' of Italy also climbed during Portugal and Ireland's bailout talks. However, strikes, $€ 54$ bn austerity package and credit rating downgrade by Standard and Poor's have resurfaced the severely problematic structure of the Italian and Spanish economies, in September 2011. Consequently, the markets have stopped following their credit risk closely.

Our analysis also supports the main results of Heinz and Sun (2014). CESEE (Central European and South Eastern European) countries are not particularly affected by the Eurozone periphery between May 2010 and June 2012. Rather EU core, EU periphery and CESEE countries are mostly affecting their own groups. The main difference is that, in our study, Russia and Turkey are the main transmitters of shocks in this period while they are relatively ineffective in Heinz and Sun (2014). One possible reason for their finding is multicollinearity, resulting from high correlation between Russia and Turkey as well as with Bulgaria. Elastic net estimation is able to deal with multicollinearity using its ridge regression component. Therefore we can see the full effect of these countries over others.

I-6: Safe havens do not have high explanatory power in the determination of SCDS spreads of other countries

Our analysis shows that sovereigns such as US, Japan, Great Britain, Australia and New 
Zealand are relatively disconnected in the samples they are included. The shocks in the SCDSs of the safe countries do not affect the remaining sovereigns by a large margin. The simplest possible reason is that the SCDSs of these countries are relatively illiquid (due to extremely small risk of default). We might be observing pseudo shocks in these sovereigns due to high bid-ask spreads. Another explanation would be that even relatively large shocks are not able to hurt the confidence of investors who hold debt of these sovereigns. Therefore, the SCDS spreads of these sovereigns do not move with the shocks which move relatively riskier SCDS spreads.

\section{Conclusions}

Using daily data on SCDS returns and volatilities we have estimated the network structure of sovereign credit risk for 38 countries. Undertaking high-dimensional network estimation for returns and volatilities separately, our paper is the first in SCDS literature. The high frequency data and the high-dimensional network estimation allowed us to analyze how credit risk spreads across a large group of sovereigns over a five year period. Our results for the full sample from 2009 to 2014 have shown that while developing and developed country groups have high within-connectedness in returns, return connectedness across the two groups is relatively weak. The analysis of volatility connectedness, on the other hand, reveals that there is higher within-region connectedness in volatility among the emerging market countries.

Utilizing the dynamic connectedness framework, we are able to analyze the network structure of the sovereign credit risk during major turning points since the global financial crisis. The results show that emerging markets are the most important transmitters of shocks, even during the Eurozone crisis. Severely problematic EU member countries, on the other hand, cease to be important transmitters of credit risk while safe havens are rarely connected to the rest of the network. These findings are completely new and intriguing in a literature where the U.S. and PIIGS countries were argued to be the largest transmitters of sovereign credit shocks.

Our analysis has also shown that, on average, global factors are far more important for the sovereign credit risk. Yet, the relative importance of domestic and global factors change significantly over time and across sovereigns. While the importance of global factors increases during crises, they are more important than domestic factors also during tranquil times. Our findings strongly tilt the debate in the literature in favor of global factors. 
Finally, as opposed to the belief in the previous literature, we have found that return shocks in other asset classes hold little value in the determination of sovereign credit risk, when a considerable amount of SCDS spreads are controlled for. Therefore, SCDS markets aggregate information considerably fast and it is sufficient for analysts to focus on SCDS spreads alone in their analysis of the behavior of SCDS spreads.

Our method has particular advantages going forward. As more detailed and correct data is collected, the number of sovereigns that can be included in the analysis increases. Since the use of elastic net allows as many variables as there are available without a need to increase the sample period, the analysts can make new estimations and observe the trends day by day.

\section{References}

Acemoglu, Daron, Asuman Ozdaglar, and Alireza Tahbaz-Salehi (2015), "Systemic Risk and Stability in Financial Networks," American Economic Review, 105, 564-608.

Acharya, V., L. Pedersen, T. Philippe, and M. Richardson (2010), "Measuring Systemic Risk," Manuscript, Stern School, New York University.

Adrian, T. and M.K. Brunnermeier (2008), "CoVaR," Federal Reserve Bank of New York Staff Reports, 348.

Aizenman, Joshua, Michael Hutchison, and Yothin Jinjarak (2013), "What is the risk of European sovereign debt defaults? Fiscal space, $\{\mathrm{CDS}\}$ spreads and market pricing of risk," Journal of International Money and Finance, 34, 37 - 59.

Alter, Adrian and Andreas Beyer (2014), "The dynamics of spillover effects during the European sovereign debt turmoil," Journal of Banking \& Finance, 42, 134 - 153.

Ang, A. and F.A. Longstaff (2013), "Systemic Sovereign Credit Risk: Lessons from the U.S. and Europe," Journal of Monetary Economics, 60(5), 493-510.

Arsov, I., E. Canetti, L. Kodres, and S. Mitra (2013), "Near-Coincident" Indicators of Systemic Stress," IMF Working Paper WP 13-115.

Augustin, P. and R. Tédongap (Forthcoming), "Real Economic Shocks and Sovereign Credit Risk," Journal of Financial and Quantitative Analysis. 
Beirne, John and Marcel Fratzscher (2013), "The pricing of sovereign risk and contagion during the European sovereign debt crisis," Journal of International Money and Finance, $34,60-82$.

Blodel, V. D., J. Guillaume, R. Lambiotte, and E. Lefebvre (2008), "Fast Unfolding of Communities in Large Networks," Journal of Statistical Mechanics: Theory and Experiment, page P10008.

Cho, D., K. Choi, and K Chung (2014), "Interconnectedness and Contagion Effects in Asian Sovereign CDS Markets," Working Paper.

D'Agostino, A. and M. Ehrmann (2013), "The Pricing of G7 Sovereign Bond Spreads: The Times, They are A-Changin," ECB Working Paper 1520.

Demirer, M., F.X. Diebold, L. Liu, and K. Yilmaz (2015), "Estimating Global Bank Network Connectedness," Manuscript, MIT, University of Pennsylvania and Koç University.

Diebold, F.X. and K. Yilmaz (2009), "Measuring Financial Asset Return and Volatility Spillovers, with Application to Global Equity Markets," Economic Journal, 119, 158171.

Diebold, F.X. and K. Yilmaz (2012), "Better to Give than to Receive: Predictive Measurement of Volatility Spillovers," International Journal of Forecasting, 28, 57-66.

Diebold, F.X. and K. Yilmaz (2014), "On the Network Topology of Variance Decompositions: Measuring the Connectedness of Financial Firms," Journal of Econometrics, 182, 119134.

Diebold, F.X. and K. Yilmaz (2015), Financial and Macroeconomic Connectedness: A Network Approach to Measurement and Monitoring, Oxford University Press.

Duffie, Darrell (1999), "Credit Swap Valuation," Financial Analysts Journal, 55, 73-87.

Favero, Carlo and Alessandro Missale (2012), "Sovereign Spreads in the Eurozone: Which Prospects for a Eurobond?" Economic Policy, 27, 231-273.

Furman, Y. (2014), "VAR Estimation with the Adaptive Elastic Net," SSRN Working Paper.

Garman, M. B. and M. J. Klass (1980), "On the Estimation of Security Price Volatilities From Historical Data," Journal of Business, 53, 67-78. 
Gyntelberg, J., P. Hördahl, K. Ters, and J. Urban (2013), "Intraday Dynamics of Sovereign CDS and Bonds," BIS Working Paper, No 423.

Heinz, F., F. and Y. Sun (2014), "Sovereign CDS spreads in Europe: The role of global risk aversion, economic fundamentals, liquidity, and spillovers," IMF Working Paper n. 14/17.

Hilscher, J. and Y. Nosbusch (2010), "Determinants of Sovereign Risk: Macroeconomic Fundamentals and the Pricing of Sovereign Debt," Review of Finance, 14, 235-262.

Jacomy, M., S. Heymann, T. Venturini, and M. Bastian (2014), "ForceAtlas2, A Continuous Graph Layout Algorithm for Handy Network Visualization Designed for the Gephi Software," PLoS ONE, 9, www.plosone.org.

Longstaff, F.A., J. Pan, L.H. Pedersen, and K.J. Singleton (2011), "How Sovereign Is Sovereign Credit Risk?" American Economic Journal: Macroeconomics, 3(2), 75-103.

Pan, J. and K.J. Singleton (2008), "Default and Recovery Implicit in the Term Structure of Sovereign CDS Spreads," The Journal of Finance, 63 Issue 5, 2345-2384.

Pesaran, H.H. and Y. Shin (1998), "Generalized Impulse Response Analysis in Linear Multivariate Models," Economics Letters, 58, 17-29.

Wang, Ping and Tomoe Moore (2012), "The integration of the credit default swap markets during the $\{\mathrm{US}\}$ subprime crisis: Dynamic correlation analysis," Journal of International Financial Markets, Institutions and Money, 22, 1-15.

Zou, H. and T. Hastie (2005), "Regularization and Variable Selection via the Elastic Net," Journal of the Royal Statistical Society, Series B (Statistical Methodology), 67, 301-320. 


\section{A Appendix: Sensitivity Analyses}

Here, in the appendix, we report the results of sensitivity analyses through which we cant to understand how sensitive our main results to changes in various parameter specifications in our connectedness analysis. First, we check the robustness of our results to the choice of the elastic net approach. Second, we check the sensitivity of the results to the rolling windows estimation approach. In particular, we check whether the dynamic connectedness index behave any different when we give more weights to more recent observation in the rolling windows. Then we allow the rolling window size to be different from 150 days and analyze the effect on our results. Then, we check for the sensitivity of our dynamic connectedness plots to the choice of two other tuning parameters, namely, the forecast horizon and the order of the VAR model. Finally, we replicate the 'connectedness' analysis using simple correlations instead of the DY connectedness methodology.

\section{A.1 Elastic Net Estimation}

Elastic Net estimation method is intuitively simple and appealing. It enables one to work with very high dimensional data, which would not be possible in the simple OLS framework. However, as any other method, it has its own drawbacks. The parameters are biased, since it does not minimize the sum of squared errors. The nature of our estimation method gives us reason to presume that the bias created by the elastic net estimation can be overlooked. However, it would be better to test this implicit assumption by comparing the results obtained from elastic net estimation to the results generated by simple OLS estimation.

In principle, the comparison can be done in small samples, however, it would be mostly inconclusive since OLS overfits when degrees of freedom is low. Indeed, the overfitting problem of OLS is the main reason behind the development and utilization of LASSO type methods. Therefore, we would expect results from the OLS estimation to be different than the results from elastic net estimation when degrees of freedom is low. In addition, our rolling window analyses for particular events cannot be replicated with OLS since degrees of freedom is negative for most of the windows. What we do instead is to replicate our full-sample graphs using OLS instead of elastic net estimation method, where we have considerable degrees of freedom. We give the results in Figure A.1. The graphs are not identical to the ones in the main text, however, all the main results we discuss in the paper still hold. Both methods produce the same clustering structure, same coloring scheme across sovereigns and same relation between the return and volatility connectedness plots in the full sample. 


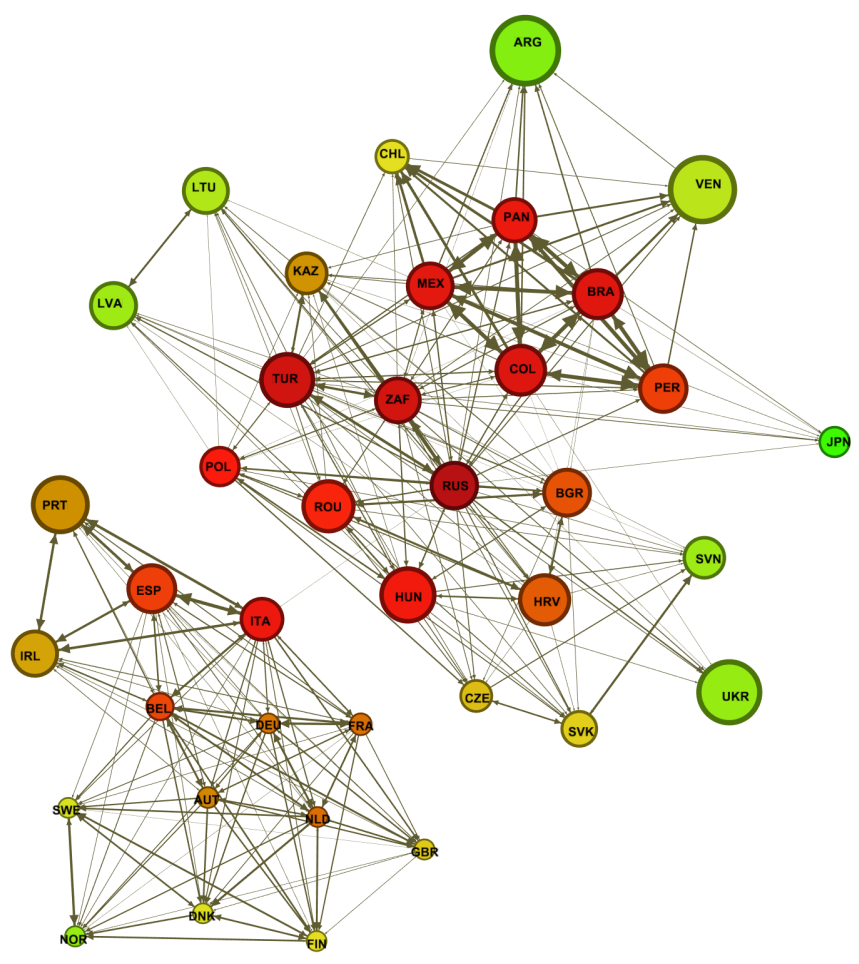

(a) Return Connectedness, Scale $=600$

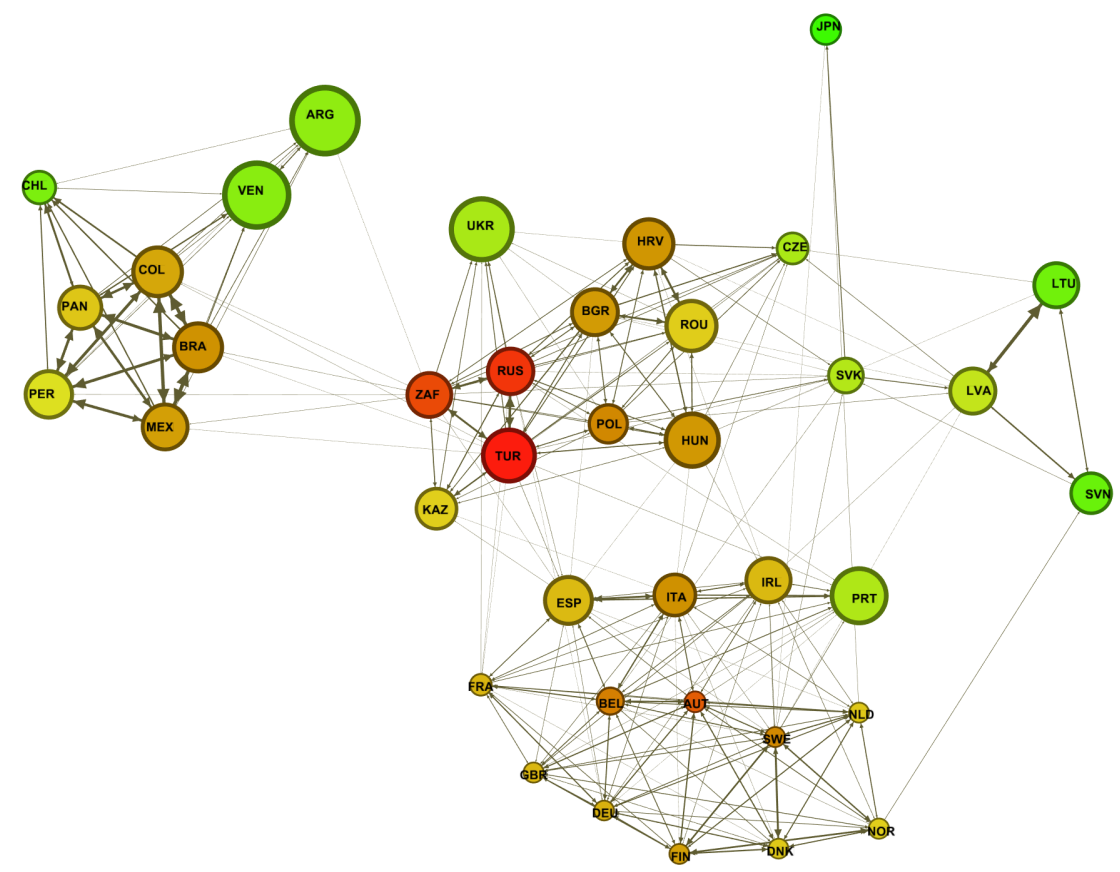

(b) Volatility Connectedness, Scale $=400$

Figure A.1: Sovereign CDS Network, 2009-2014 using OLS (25\% of the edges visible) 
Another tricky side of the elastic net estimation method is determination of the shrinkage coefficient $\lambda$. The classic method is cross-validation. However, in time series data, the errors are correlated and $\lambda$ determined by cross validation may not be the correct one. In the dynamic analysis, we cross validate $\lambda$ for each window separately. To measure the dependence of our results on the $\lambda$ parameter, we conduct the dynamic analysis using only the smallest and largest $\lambda$ values without doing any cross validation.

\section{A.2 Tuning Parameters}

Our connectedness measures depend on three choice variables, namely, the order of the VAR model (that is, the number of lags of endogenous variable included), rolling window size and forecast horizon. It's impossible to test all our results for different choices of these variables. Thus, we test sensitivity of dynamics of our system-wide connectedness index and our full sample network graphs. Our usual choices for these variables are 3 for the order of the VAR model, 150-days for the size of the rolling window and 10-days for the forecast horizon. We present results for 2 and 4 lags, 100-day and 200-day rolling windows and 3-day forecast horizon ${ }^{27}$. We will only focus on return connectedness in this section, since volatility connectedness results are very similar.

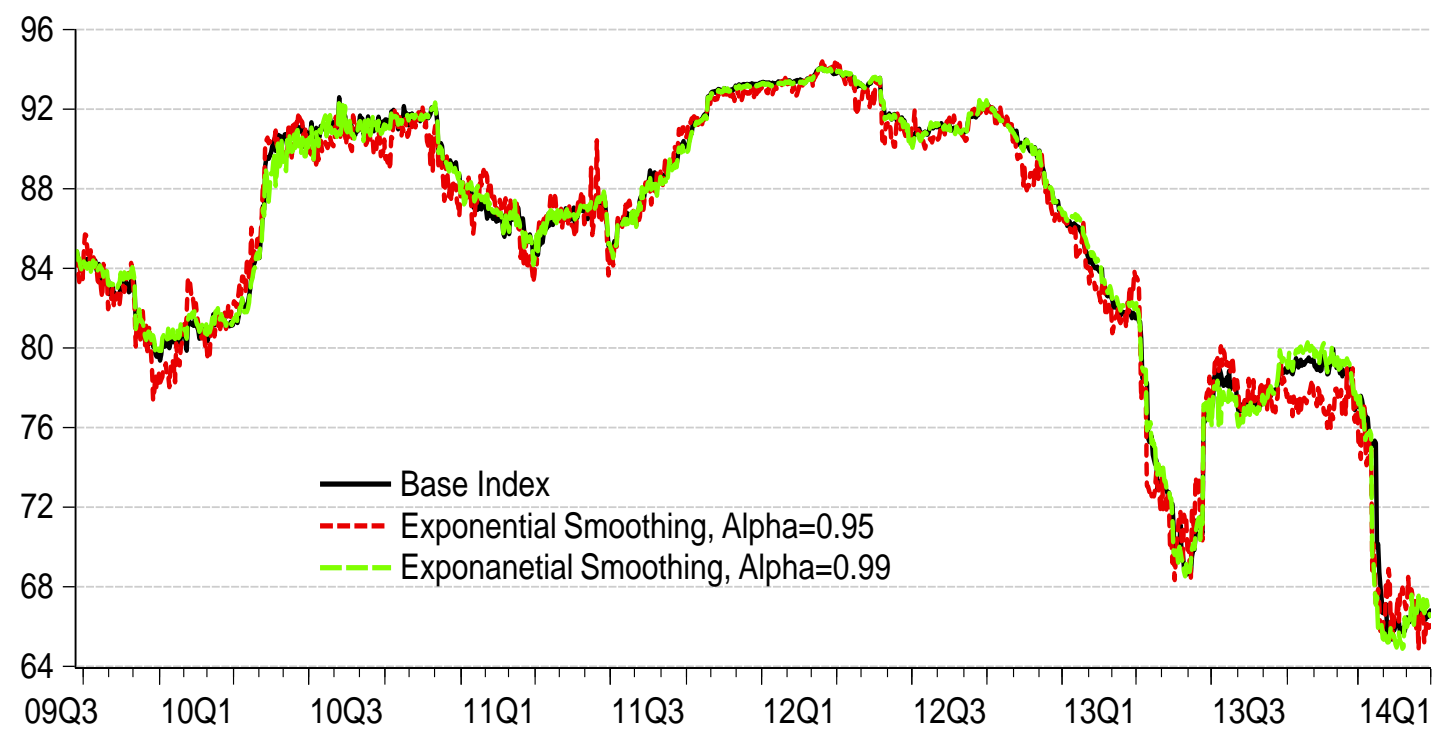

Figure A.2: Sensitivity of Connectedness Index to Exponential Smoothing

\footnotetext{
${ }^{27}$ We will not present results for forecast horizons more than 10 days. Variance decomposition matrices are almost identical after 10 days, thus our results remain basically the same as we increase our forecast horizon
} 
Before focusing on the sensitivitiy of the results to the tuning parameters, in Figure A.2, we allow for exponential smoothing, where more recent observations have larger weights in estimation. As the weight given to the more recent observations increases, the index becomes more ragged. However, our main results obtained with equal weights to all observations included in the rolling window do not change.

In Figure A.3, we present results regarding the sensitivity of our system-wide connectedness index to rolling window size. We use 150-day rolling window size in our main analysis. Here we compare it with 100-day and 200-day rolling windows. The index becomes more responsive to shocks as the size of the rolling window decreases, as expected. Our main results still hold, with one exception. When the window size becomes 200 days, effect of Bernanke's speech becomes less persistent. Index never decreases after the Euro crisis in the first place, so observing a smaller effect might be misleading when the window size is too large.

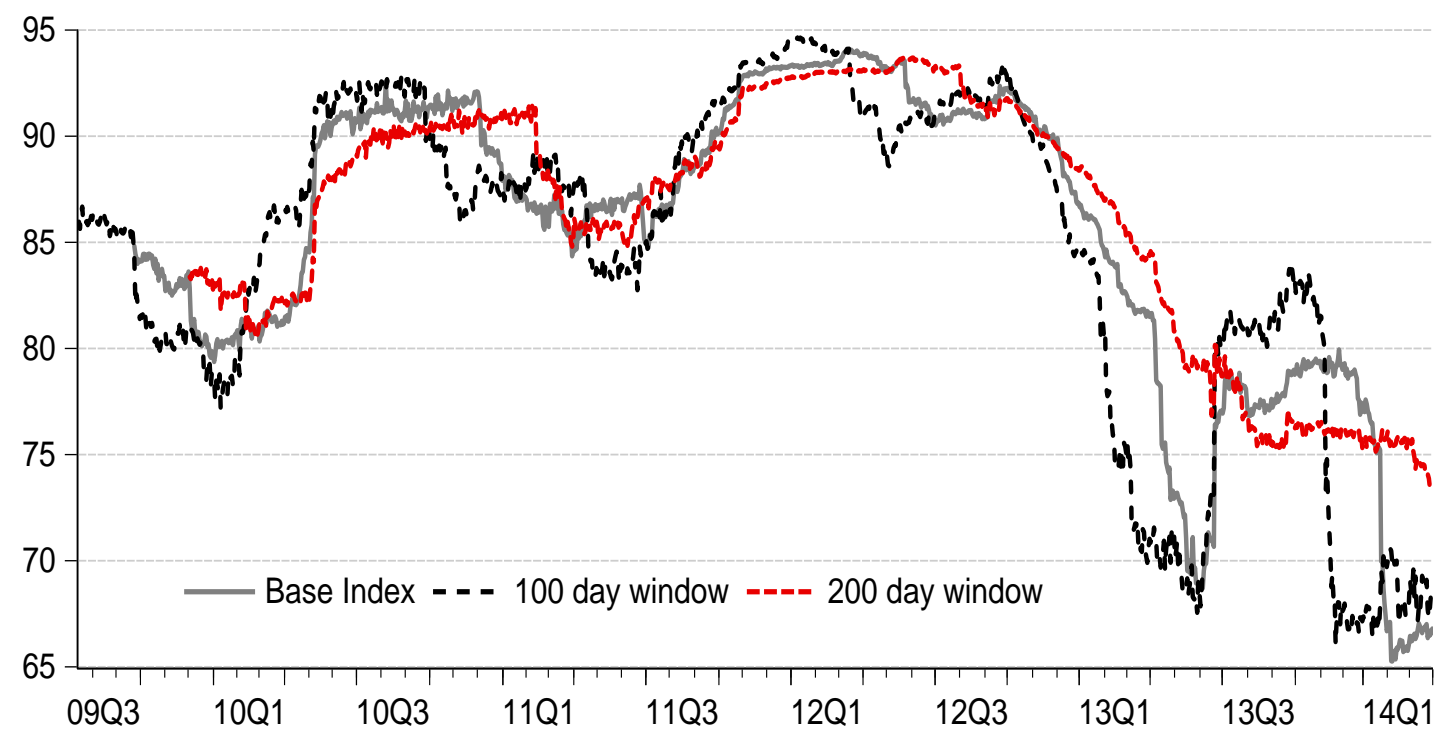

Figure A.3: Sensitivity of Connectedness Index to Rolling Window Size

We decided not to present the results of the sensitivity analysis of our system-wide connectedness index to forecast horizon only, since the plots of the connectedness index for different forecast horizons are virtually indistinguishable. Instead, we focus on the sensitivity of our results to simultaneous changes in tuning parameters, that is, the forecast horizon, the window size as well as the order of the VAR model and present the results in Figure ??. The dynamic system-wide connectedness index plot can vary substantially when all three tuning parameters are changed simultaneously. In Figure A.4, we present results for a sample of 


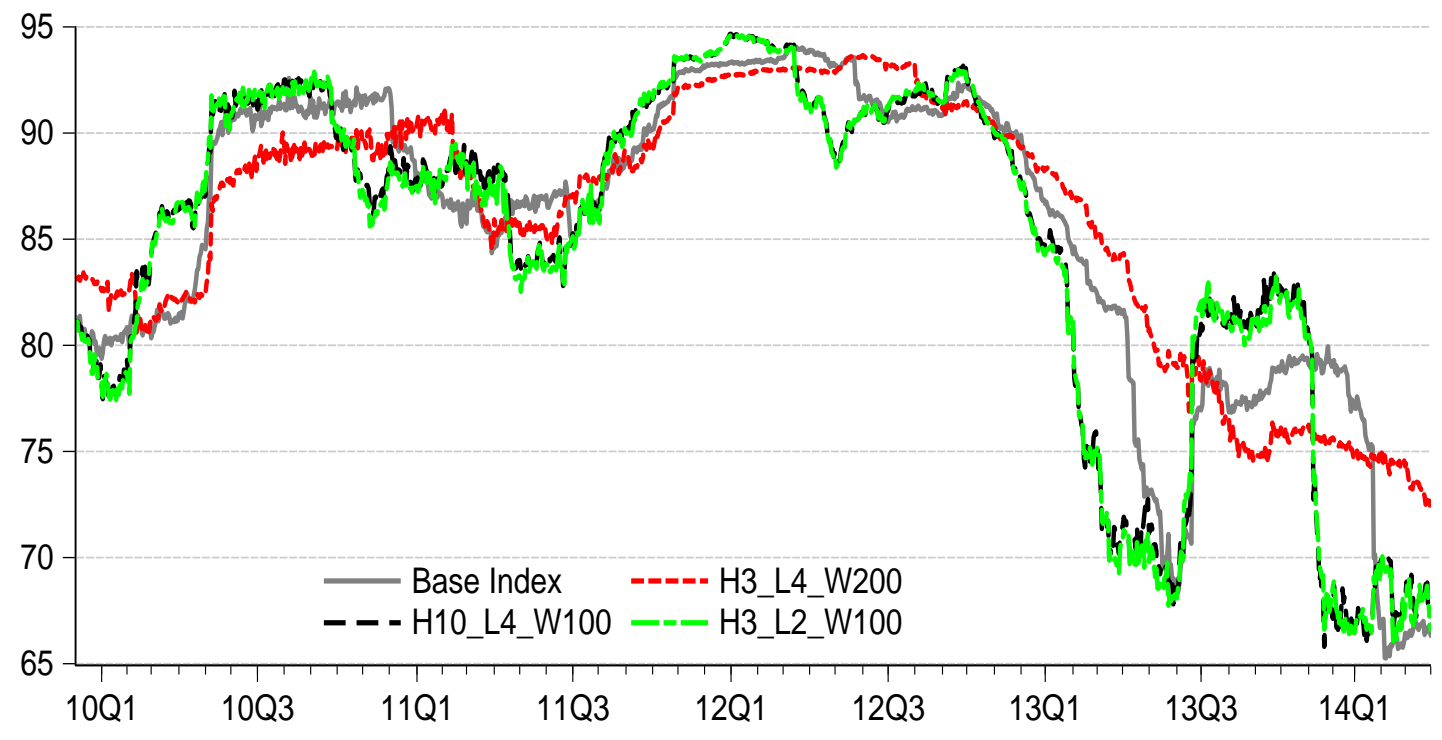

Figure A.4: Sensitivity of the Connectedness Index to Three Tuning Parameters

changes in our tuning parameters. We allow the forecast horizon to be 3 and 10 days, the window size to be 100 and 200 days and the order of VAR model to be 2 and 4 days. What we observe is that the main changes in the graphs are still dictated by the changing rolling window size. We do not observe a specific effect by the interaction of changes in multiple parameters. 